\title{
Physical Frailty/Sarcopenia as a Key Predisposing Factor to Coronavirus Disease 2019 (COVID-19) and Its Complications in Older Adults
}

\author{
Amira Mohammed Ali ${ }^{1,2, *(D)}$ and Hiroshi Kunugi ${ }^{3,4}$ \\ 1 Department of Behavioral Medicine, National Center of Neurology and Psychiatry, National Institute of \\ Mental Health, Tokyo 187-8553, Japan \\ 2 Department of Psychiatric Nursing and Mental Health, Faculty of Nursing, Alexandria University, \\ Alexandria 21527, Egypt \\ 3 Department of Psychiatry, Teikyo University School of Medicine, Tokyo 173-8605, Japan; \\ hkunugi@med.teikyo-u.ac.jp \\ 4 Department of Mental Disorder Research, National Center of Neurology and Psychiatry, National Institute of \\ Neuroscience, Tokyo 187-8502, Japan \\ * Correspondence: mercy.ofheaven2000@gmail.com; Tel.: +81-042-346-1714
}

Citation: Ali, A.M.; Kunugi, H. Physical Frailty/Sarcopenia as a Key Predisposing Factor to Coronavirus Disease 2019 (COVID-19) and Its Complications in Older Adults. BioMed 2021, 1, 11-40. https:// doi.org/10.3390/biomed1010002

Academic Editor: Marc Poirot

Received: 18 May 2021

Accepted: 23 July 2021

Published: 29 July 2021

Publisher's Note: MDPI stays neutral with regard to jurisdictional claims in published maps and institutional affiliations.

Copyright: (c) 2021 by the authors. Licensee MDPI, Basel, Switzerland. This article is an open access article distributed under the terms and conditions of the Creative Commons Attribution (CC BY) license (https:// creativecommons.org/licenses/by/ $4.0 /)$.
Abstract: The tremendously rising numbers of aged populations are associated with a heightened risk for motor and functional declines. Sarcopenia is an active age-related process that involves progressive losses of skeletal muscle mass, muscle strength, and muscle function. Muscle failure is a major cause of frailty, disability, falls, hospitalization, dependency, institutionalization, and low quality of life in older seniors. Therefore, sarcopenia considerably heightens the annual cost of care worldwide. This narrative review elaborates on sarcopenia as a deleterious condition in old age while spotting the light on its association with the coronavirus disease 2019 (COVID-19). It discusses its pathophysiology and the most possible options for preventing and treating sarcopenia. The literature shows that the dynamic of sarcopenia is complex, involving multifaceted physiological alterations relevant to aging, unhealthy behaviors (e.g., undernutrition or inadequate dietary intake and physical inactivity/immobility or sedentary lifestyle), and multiple pathogenic conditions such as metabolic, inflammatory, and endocrinal disorders. Frail individuals express nutritional deficiencies, immune deficit, oxidative stress, metabolic alterations, gut microbial alterations, neurological insult, etc. Such physiological dysfunctions are closely linked to increased vulnerability to COVID-19 among older adults and people with non-communicable diseases such as diabetes mellitus, cardiovascular disorders, and obesity. Available studies report higher occurrence of severe COVID-19 and COVID19-related complications (ICU admission, mechanical ventilation, and in-hospital mortality) among frail compared with non-frail and prefrail individuals. Effective pharmacological treatments of sarcopenia are not currently available. However, physical activity and nutritional interventions (e.g., fast digestive proteins, vitamin D, and natural products such as bee products) may prevent the development of sarcopenia in early stages of the disease or limit disease progress. Such interventions may also lower vulnerability to COVID-19.

Keywords: coronavirus disease 2019; COVID-19; severe acute respiratory syndrome; SARS-CoV-2; sarcopenia; dynapenia; frailty; cachexia; malnutrition; obesity; sarcopenic obesity; aging; dietary interventions; neuromuscular; muscle; skeletal; muscle wasting; muscle mass; muscle strength; gut-muscle axis; physical performance; body composition; lean body mass; insulin resistance; mitochondrial dysfunction; satellite stem cells

\section{Introduction}

Worldwide, the numbers of elderly people are on the rise [1]. It is expected that by 2050 , the population over 60 years will exceed 2 billion people, and more than 400 million will be 80 years or older [2]. Aging is associated with several changes in body composition 
such as accumulation of body fat, loss of muscle and bone mass, and joint inflexibility. Such alterations increase the occurrence of various motor dysfunctions, which lead to a progressive decline of functional capacity, heightened mobility limitations, high disability and dependency in older groups [2-4].

Muscular atrophy is a key feature of advanced aging. After the age of 30, age-related muscle mass loss is characterized by a 3-8\% decline per decade, and at the age of 50 years, lean body mass (LBM) loss occurs at a rate of $1-2 \%$ per year. Then, it develops progressively with the increase of age [5-7]. Lean body mass or non-fat mass refers to the weight of all body components other than fat (e.g., bones, muscle, connective tissues, other protein-rich structures like enzymes and viscera, water, and minerals). Muscle mass refers to the total weight of skeletal muscle, and it represents the majority of lean body mass [7]. Sarcopenia is a common age-related syndrome that comprises loss of muscle mass and function [8,9]. The current International Classification of Diseases considers sarcopenia as a specific agerelated disease [10-12]. The prevalence of sarcopenia in the general elderly population ranges between 3\% and 59\% (this difference depends on sarcopenia definition, evaluation tools, and age category), with the highest prevalence occurring in individuals aged 80 years or above [13-17]. Sarcopenia represents a public health problem given its high prevalence and its association with numerous serious adverse effects that range from muscle ache and falls to premature death $[11,18]$.

Coronavirus disease 2019 (COVID-19) is a highly-spreading respiratory viral infection caused by severe acute respiratory syndrome-coronavirus-2 (SARS-CoV-2) $[19,20]$. SARS$\mathrm{CoV}-2$ induces excessive inflammatory and oxidative responses that cause severe acute respiratory distress syndrome (ARDS), multiple organ failure, sepsis, and mortality [20-22]. Such adverse effects are mostly endured by aged individuals and people with chronic disorders (e.g., obesity, cardiovascular diseases, type 2 diabetes, etc.) [21,23-26]. The prevalence of these diseases is high among older adults, which increases their likelihood for contracting SARS-CoV-2 and encountering the detrimental effects of this virulent infection [23,25]. The development of COVID-19 in people with sarcopenia is associated with poor prognosis and high fatalities identifying sarcopenia as a major risk factor for the detrimental effects of COVID-19 [27-32]. In this light, the current review elaborates on muscle dysfunction in old age while spotting the light on its association with vulnerability to COVID-19 and its complications. It also summarizes data from recent studies regarding the pathophysiology of sarcopenia and describes the most possible options for its prevention and treatment as an attempt to reduce the risk for COVID-19 in old age. Studies used to support this narrative review were obtained through hand search in PubMed and Google Scholar using combinations of relevant terms such as sarcopenia, muscle loss, physical frailty, skeletal muscle, aging, COVID-19, coronavirus disease 2019, oxidative stress, inflammation, metabolism, gut-microbiome/microbiota, neuromuscular degeneration, malnutrition, cachexia, physical activity, sedentary life style, complications/consequences/adverse effects, sarcopenia treatment/s, and nutritional interventions for sarcopenia.

\section{Overview of Age-Related Effects on Skeletal Muscle}

Skeletal muscle constitutes around $40 \%$ of adult human body mass [11,15]. It is a complex paracrine organ with myokine secretions that contribute to the metabolism of the whole body. It can support energy demand during extreme metabolic perturbation via its glucose and amino acid stores [33,34]. It plays a major role in core bodily processes such as breathing, bone and neuromuscular function, gait maintenance, and locomotion $[33,35]$. Skeletal muscle comprises multiple tissue structures including myofibers or multinucleated cells-the main contributor to muscle quantitative and qualitative properties-neurons, connective tissues, and vasculature networks $[11,36]$. A single human muscle may contain different proportions of fiber types [37]. Muscle fibers in mammals are classified into slow-twitch (type I) or fast-twitch (types IIa, IIb, and IIx/d) according to their speed of contraction and myosin ATPase enzyme forms revealed in histochemical analysis $[11,38]$. According to the level of energy metabolism, type I fibers are insulin sensitive and oxidative 
of fatty acids whereas type II fibers are largely glycolytic or oxidative-glycolytic. The proportion of type I and type II fibers in each muscle changes with aging because muscle fibers remodel their phenotypes [37].

Aging triggers loss of both slow-twitch type I and fast-twitch type II fibers as well as their motor units, which represent the last functional units of the motor system $[2,15,39]$. However, type I fibers are more vulnerable to inactivity and denervation-induced atrophy more than age-related atrophy. On the other hand, most age-related atrophy affects type II fibers, and it occurs gradually starting from midlife. Multiple external stimuli and experiences that muscle fibers witness during the aging process activate different signaling pathways that can damage muscle fibers by promoting fast-to-slow transformation of fiber type composition [2,38]. For instance, fast type II fibers shift toward oxidative metabolism rather than glycolytic metabolism due to their high need for adenosine tri-phosphate (ATP, the main energy unit for cellular processes) in order to create tension necessary to perform daily tasks $[15,38]$. They commonly shrink and lose their function in response to inflammatory signaling associated with transforming growth factor- $\beta$ (TGF- $\beta$ ) family and the nuclear factor kappa B (NF- $\mathrm{kB})$, which are predominantly upregulated in aged people and diseased conditions e.g., cancer, diabetes, and chronic heart failure [2,37]. Sarcopenia is a direct result of the shrinkage and atrophy of fast-twitch type II muscle fibers and loss of their motor units [15].

\section{Definitions of Sarcopenia}

Sarcopenia was originally introduced by Rosenberg in 1989 to describe eminent alterations in body composition and related functions. The term "sarcopenia" originates from two Greek words: sarx and penia, which mean flesh and loss, respectively [40]. It was first defined as an appendicular skeletal muscle mass (ASM, $\mathrm{kg}$ ) per height in meters squared $\left(\mathrm{m}^{2}\right)$ of two standard deviations (SDs) below the normal mean of a young healthy reference population (20-30 years old) $[17,35,41]$. Then, other related terms erupted such as dynapenia-low muscle strength $[13,35,42]$. Dynapenia is more frequent in older population than sarcopenia by 2 -fold, and it entails an increased percentage of body fat despite unaffected skeletal muscle mass index (SMI) [13]. Compromised physical function is another related condition, which is evaluated by gait speed, 4-m walking speed, and sit-to-stand tests $[7,35]$. In fact, age-related muscle dysfunction comprises a combination of low muscle mass, muscle strength, and physical function [5]. In the meantime, neither of these conditions can completely describe quantitative and qualitative muscular changes or predict associated disability, which implies that the concept of sarcopenia is still developing $[5,7,16,41]$.

In the last few years, the European Working Group on Sarcopenia in Older People (EWGSOP), the European Working Group on Sarcopenia in Older People 2 (EWGSOP2), the International Working Group on Sarcopenia (IWGS), and the Asian Working Group for Sarcopenia (AWGS) have reached a consensus to include measurements of muscle strength and physical performance in the definition of sarcopenia $[5,7,16,35,41]$. These four bodies developed a practical clinical definition of sarcopenia as "a syndrome of progressive and generalized loss of skeletal muscle mass and strength, which is associated with an increased risk of adverse outcomes like disability, poor quality of life (QoL), and death" [5,16]. In addition, they established an algorithm for diagnosing sarcopenia based on the presence of low muscle mass in addition to low muscle strength or low physical performance $[7,11]$.

\section{Classifications of Sarcopenia}

Different classifications of sarcopenia are described in the literature (Figure 1). These classifications have different bases: the extent of muscle mass loss, the etiological drives of muscle mass loss, and the disease stage as indicated by loss of muscle strength or physical performance along with muscle wasting. 


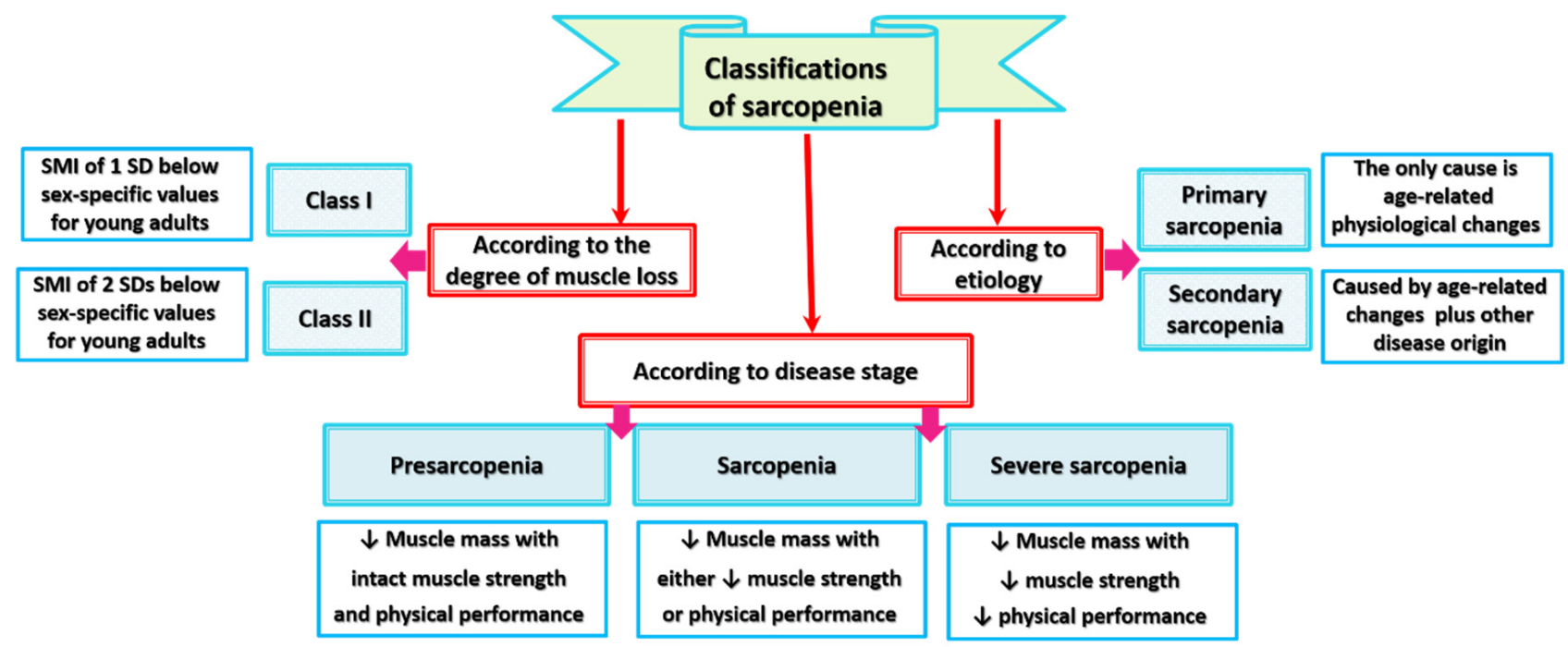

Figure 1. Different classifications of sarcopenia. Abbreviations: $\downarrow$ denotes decrease, SMI: skeletal muscle mass index, SDs: standard deviations.

Sarcopenia in adults aged 50 years or older is classified into class I and II sarcopenia based on an SMI of one or two SDs below sex-specific values for young adults $[43,44]$. Above the age of 50, class I and class II sarcopenia are more prevalent among women (up to $61 \%$ and $11 \%$, respectively) than men (up to $47 \%$ and $7 \%$, respectively) $[7,43]$. Although age-related loss of muscle mass is gradual, concurrent steep reductions in muscle strength occur $[5,7]$. Moreover, older individuals with class II sarcopenia experience 2-3-fold higher functional impairment than people with normal muscle mass, even after adjusting for age, race, body mass index (BMI), health behaviors, and comorbidities [7,43]. Given that the loss of muscle fiber does not necessarily reduce muscle performance, attention has been focused on functional aspects of the disease. Qualitative muscle changes, as reflected by drop of muscle strength and power, result from declines in the intrinsic force-generating capacity of skeletal muscle fibers [2]. Taking into account the force corrected for size factor into consideration, EWGSOP classified sarcopenia into three stages: (1) presarcopenia, which describes low muscle mass with intact/unaffected muscle strength and physical performance, (2) sarcopenia, which describes low muscle mass accompanied by either low muscle strength or low physical performance, and (3) severe sarcopenia, which describes concurrent reduction of muscle mass, muscle strength, and physical performance [45].

EWGSOP classified sarcopenia according to its pathological etiology into primary and secondary types [45]. Sarcopenia represents an age-related active process that affects all individuals reaching adult life [7]. In this respect, primary or age-related sarcopenia is equivalent to idiopathic sarcopenia since no other causes contribute to skeletal muscle dysfunction except physiological alterations that occur with natural aging (e.g., increase of inflammatory biomarkers, loss of motor neurons, mitochondrial dysfunction, metabolic and endocrine changes such as decreased levels and activity of insulin-like growth factor 1 (IGF-1) and testosterone) [7,45,46]. Secondary sarcopenia results from aging-related physiological impairments in addition to one or more other pathological causes that can be identified by a diagnostic work-up $[5,15,45,46]$. Regarding the multifactorial pathologies that provoke skeletal muscle failure, secondary sarcopenia can be distinguished into several types [46]: activity-related sarcopenia, which results from physical inactivity and sedentary lifestyle, nutrition-related sarcopenia, which results from suboptimal food intake and gastrointestinal (GI) diseases that cause malabsorption, and disease-related sarcopenia, which results from inflammatory diseases and debilitating disorders associated with advanced organ failure such as cancers, rheumatoid arthritis, and heart diseases [5,7]. These demarcations between primary and secondary sarcopenia are essential for effective therapy planning because further deteriorations in muscle mass and function can be mitigated or 
prevented by proper treatment of the underlying secondary causes [15]. In this context, old COVID-19 patients with secondary sarcopenia may require special attention because of their high likelihood to develop more adverse events.

\section{Sarcopenia and Related Syndromes}

\subsection{Sarcopenia, Frailty, Cachexia, and Malnutrition}

The concept of sarcopenia overlaps with other syndromes common in old age such as malnutrition, cachexia, and frailty [41]. The literature documents concurrent occurrence of these syndromes in geriatric patients [47]. Protein-energy malnutrition results from starvation or inadequate food intake, which leads to loss of both fat free mass and fat mass. It responds to refeeding, but when not treated, it contributes to sarcopenia and frailty [48,49] (explored in depth in Section 6.8). The term "cachexia" describes excessive unintentional weight loss among individuals suffering from chronic debilitating diseases such as cancer. Its prevalence in the general patient population is $1 \%$ and in cancer patients is $50-80 \%[14,50,51]$. Most patients with cachexia and malnutrition are sarcopenic - disease-related and nutrition-related secondary sarcopenia $[15,48]$. Sarcopenia, along with malnutrition and cachexia, is a major contributor to suboptimal physical performance and frailty (Figure 2) [6,47,52]. Frailty is a late-life condition of heightened physical and/or psychological vulnerability to stressors. This aging-bound vulnerability stems from decreased capacity to keep homeostasis [6,52].

The concept of frailty is poorly understood [53]. Two theoretical frameworks characterize frailty: "multidimensional frailty/deficit approach" proposed by Rockwood and Mitnitski [54] and a unidimensional construct of "physical frailty/frailty phenotype" proposed by Fried and colleagues [55]. Rockwood and Mitnitski view frailty as a nonspecific multidimensional outcome of the accumulation of age-related defects. They conceptualized "defects" as age-related characteristic changes and functional declines, symptoms, signs, disorders, comorbidities, and disabilities [54]. According to this theory, frailty comes into four forms: physical, mental/cognitive, social, and nutritional. However, the complexity of this model hinders its applicability in research or clinical settings [5]. Physical frailty described by Fried constitutes a midway state between frailty and sarcopenia where muscle atrophy is considered a biological substratum [17]. According to Fried, physical frailty exists when an older adult expresses three out of five criteria: (1) unintentional weight loss $\geq 4.5 \mathrm{~kg}$ in the previous year (2) muscle weakness: $20 \%$ lower hand grip strength, adjusted for gender and BMI; (3) lack of energy e.g., self-reported exhaustion and low peak oxygen uptake; (4) slowness measured by the 4-m gait speed test, adjusted for gender and height; and (5) low physical activity level based on a weighted score of kilocalories expended per week, adjusted for gender (males: <383 kcals/week; females: 270 kcals/week) [5,17,53,55].

Sarcopenia, malnutrition, cachexia, and frailty are inter-related regarding their physical aspects, underling etiological factors, and adverse effects (e.g., disability, dependency, institutionalization, falls, and premature death) $[14,15,49,53]$. Weight loss is the most common feature in all these conditions [48]. Slight variations distinguish these syndromes from each other. Tissue loss in sarcopenia and frailty involves mainly loss of muscle tissue $[7,17,35,41]$ while malnutrition and cachexia involve loss of both non-fat mass and fat mass $[14,48-50]$. A key difference between malnutrition and cachexia is that tissue loss in cachexia is extensive, it occurs very early, and it responds poorly to dietary interventions [48]. Functional decline, general weakness, exhaustion, and low physical activity are common in all these conditions [49].

Muscle wasting and muscle weakness result from higher rates of muscle protein degradation that occurs in etiologies shared by these conditions: failure of multiple physiological systems, physical inactivity, decreased food intake, increased energy requirements, oxidative stress, inflammation, hormonal changes (e.g., decreased insulin and testosterone and increased cortisone), etc. [14,48,49] (all these factors are discussed in detail in Section 6). Negative regulators, which contribute to muscle atrophy, are more profound in cachectic muscle than in sarcopenic muscle (e.g., atrogin-1, ubiquitin-proteasome system (UPS), 
muscle ring finger-1 (MuRF1), NF- $\mathrm{kB}$, myostatin, etc.). This explains the progressive nature of muscle loss in sarcopenia and the steep nature of muscle loss in cachexia $[14,51]$.

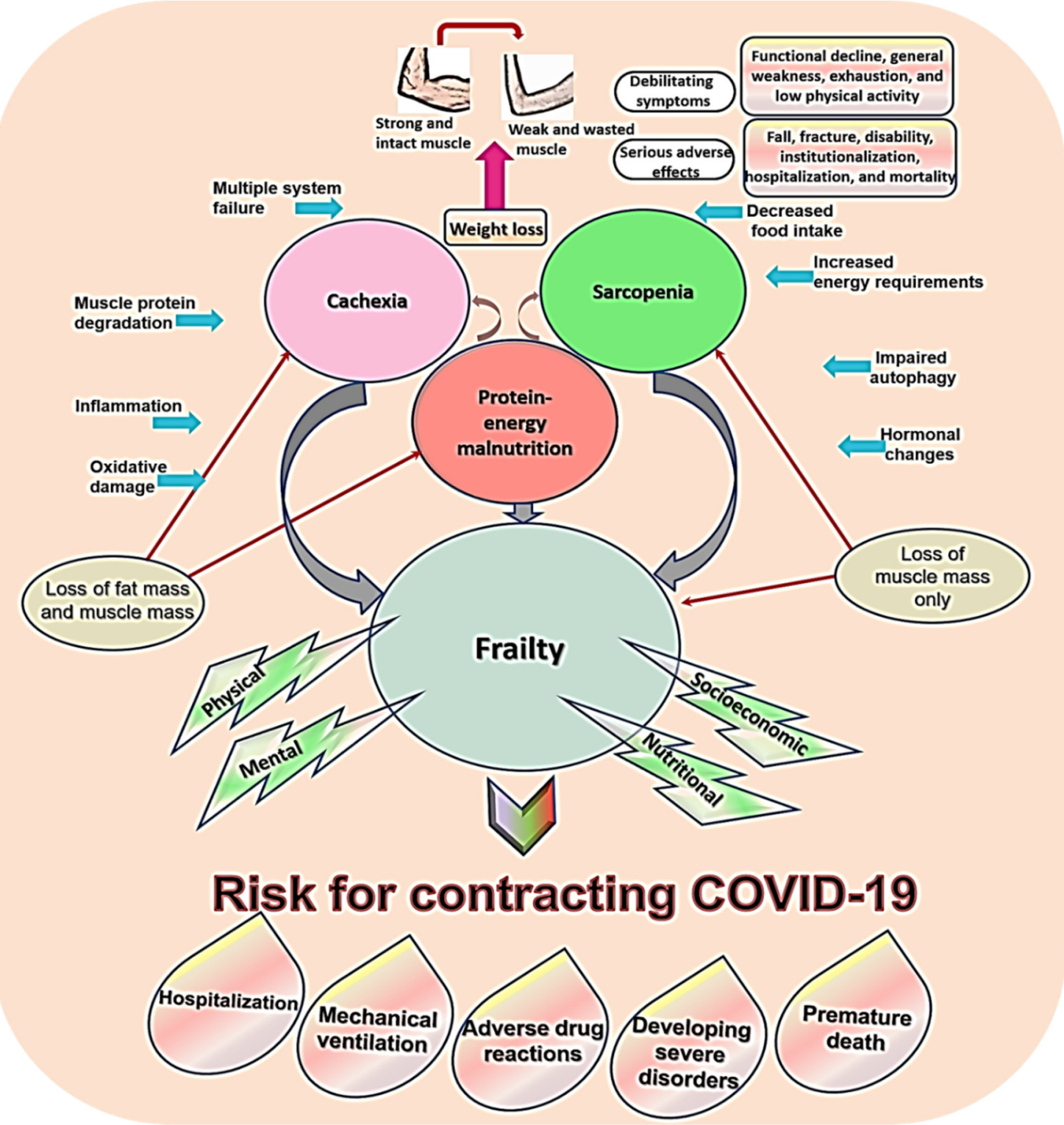

Figure 2. Schematic illustration of the commonalities between sarcopenia, frailty, cachexia and malnutrition and their association with Coronavirus Disease 2019 (COVID-19). Sarcopenia, frailty, cachexia, and malnutrition share similar etiological factors such as decreased food intake, increased dietary requirements, inflammation, oxidative damage, hormonal changes, etc. Untreated protein-energy malnutrition contributes to the onset of sarcopenia in older adults and cachexia in people with serious diseases such as cancer. Meanwhile, sarcopenia, cachexia, and malnutrition, along with all the aforementioned etiological factors disturb homeostasis and promote vulnerability to numerous stresses in late life, a condition known as frailty. Frailty comprises an early stage of physical, mental, nutritional, and socioeconomic disabilities that are bound to old age. Weight loss, which entails extensive muscle wasting and weakness, is the most common feature in these syndromes. Muscle wasting leads to numerous other debilitating symptoms such as functional decline, general weakness, exhaustion, and low physical activity. Common serious adverse effects that occur in these conditions include fall, fracture, disability, institutionalization, hospitalization, and mortality. Elders with these syndromes, especially frailty, express a considerable likelihood for contracting COVID-19. Furthermore, frailty in people with COVID-19 contributes to numerous adverse outcomes such as hospitalization, prolonged hospital stays, mechanical ventilation, adverse drug reactions, developing serious disorders, and death. 


\subsection{Sarcopenic Obesity}

Although weight loss is common in old age, individuals who do not lose weight can also experience muscle wasting, which is encountered by up to $78 \%$ of geriatric patients [15,49]. In fact, advanced age is associated with increased contents of saturated ceramide and diacylglycerol fatty acids. These compounds contribute to myosteatosis and infiltration of fatty and fibrotic tissues into skeletal muscle, eventually leading to increased fat mass along with muscle wasting and weakness $[15,37,56,57]$. On the other hand, loss of non-fat mass occurs simultaneously with obesity, which may be experienced by more than $25 \%$ of geriatric patients [49]. Obesity may even occur in older adults with cancer who usually undergo excessive muscle wasting [58]. Sarcopenic obesity is a term that describes the co-occurrence of sarcopenia with obesity $[59,60]$. It is defined as suboptimal muscle mass in relation to total body size [61]. Sarcopenic obese elders are at a great risk for frailty, immobility, cardiac disorders, etc. However, they most commonly go unnoticed since their muscle loss is masked by high fat mass [37,49].

The International Guideline Consensus Committee describes sarcopenic obesity as a malnutrition-induced chronic condition imposed by persistent mild-to-moderate inflammation [7]. Adiposity is an immunocompromising condition, which induces several molecular adversities, with chronic systemic inflammation the most prominent among all $[15,25]$. Particularly, adipose tissue dysfunctions promote local recruitment and activation of macrophages and related toll-like receptors 4 (TLR4), which act as potential sources of inflammation [61,62]. Cytokines play a major role in muscle wasting: they alter muscle protein catabolism by hindering hormones that regulate muscle metabolism such as insulin [15,60-62]. In addition, cytokines promote the production and activity of myostatin, a negative regulator of muscle protein closely linked to tumor necrosis factor- $\alpha$ (TNF- $\alpha$ ) signaling. Myostatin is a major contributor to oxidative damage, metabolic alterations, and further inflammatory pathologies in sarcopenic obese patients [59] (see Sections 6.1 and 6.2 for more details).

\subsection{Risk for COVID-19 in Sarcopenia and Related Conditions}

Low skeletal muscle mass and sarcopenic obesity evoke endothelial inflammation and functional decline [63]. Endothelial injury is associated with the severity of pulmonary insult in COVID-19 [64]. Poor muscle mass and strength negatively correlate with the respiratory muscle strength, which is reflected by maximum expiratory pressure [65]. Therefore, sarcopenia may exacerbate pulmonary function in older COVID-19 patients [36,66]. Furthermore, longitudinal data denote that low skeletal mass and sarcopenic obesity are associated with an increased risk for renal injury—indicated by developing albuminuria [67]. Renal injury is a common organ failure that develops early in 25.7\% of severe COVID-19 patients, who are mostly older adults $[68,69]$.

Given that chronic inflammation is a key molecular event associated with adiposity [15], alterations in the adipokine profile contribute to numerous physical and neurological comorbidities such as diabetes mellitus, hypertension, and Alzheimer disease $[26,56,57,70,71]$. Sarcopenic obesity, along with these associated disorders, is a confirmed risk factor for COVID-19 and its fatalities [20,23,71,72]. Adipokine dysfunction weakens the immune system, thus directly increases the vulnerability of patients with obesity to COVID-19 [25]. Furthermore, high fat mass exacerbates COVID-19 outcomes by undermining the alveolar microenvironment to promote viral pathogenesis and pulmonary migration of immune cells to evoke a maladaptive cycle of systemic and local inflammation resulting in various secondary injuries [26]. On the other hand, the COVID-19 pandemic is likely to increase the prevalence of sarcopenic obesity by discouraging physical activity through stay home policies [71,73-75] and lowering the availability of healthy food due to turndown of food production during the outbreak $[73,76]$.

Malnutrition either protein-energy or micronutrient deficiency disintegrates the immune system and triggers chronic inflammation [66,77]. Therefore, emaciated individuals including nutritionally frail older adults are highly vulnerable to COVID-19 and are more 
likely to develop severe adverse effects of the disease [23]. Section 6.8 provides a detailed illustration of malnutrition.

As illustrated in Figure 2, malnutrition, cachexia, and sarcopenia contribute to frailty, which is a major factor that predisposes old people to COVID-19 and its complications $[28,32,78]$. Prospective data from China and Europe show a high prevalence of frailty among patients hospitalized because of COVID-19. In a study screening 1564 European patients with COVID-19 through Clinical Frailty Scale (CFS) on hospital admission, $49.4 \%$ were classified as frail (CFS 5-8) and 1.7\% were classified as terminally ill (CFS 9) [32]. Similar results were reported in other samples of European older adults [30,69]. In China, screening of hospitalized elders with confirmed COVID-19 through the FRAIL scale, revealed that $34.2 \%$ and $31.6 \%$ were pre-frail and frail, respectively [78].

Although polypharmacy in old seniors with COVID-19 is not associated with mortality [30], simulation studies show that frail elders who receive repurposed drugs for the treatment of COVID-19 are at a high risk for developing adverse drug events-the risk increases with polypharmacy [29]. Moreover, frailty is a key predictive factor for poor prognosis and mortality in patients with COVID-19 [28,29]. It is suggested that the use of frailty as a predictor of poor prognosis can be more informative than the use of age or comorbidities for this purpose because frailty in COVID-19 has been also noted in young individuals $[31,32,36,66]$. In this regard, elders with higher Frailty Index (FI) are at high risk for intensive care unit (ICU) admission [31]. COVID-19 patients who score 4 or more on the CFS at hospital admission have a significantly higher risk for requiring mechanical ventilation after adjustment for age, Charlson Comorbidity Index, and quick sepsis-related organ failure score. On the other hand, patients with earlier discharge from the hospital have lower CFS scores (hazard ratio (HR) $=0.554$, CI: 0.312-0.983, $p=0.043$ ) [28]. Pre-frail and frail older adults with COVID-19, in order, express a greater hazard risk (HR) for developing 43 severe disorders ( $\mathrm{HR}=5.01,95 \% \mathrm{CI} 1.16-21.61, p=0.03)$ and $(\mathrm{HR}=7.47$, $95 \%$ CI 1.73-32.34, $p=0.007$ ) than their non-frail counterparts [78]. Moreover, moderate to severe frailty (CFS 6 and higher) is associated with all-cause mortality risk in older patients with COVID-19 [79]. Deaths on day 7 of hospital admission were exceptionally high in frail (CFS 5-6, adjusted odds ratio (AOR) $=1.62$ CI: $0.81-3.26)$ and severely frail (CFS 7-9, AOR = 3.12 CI: 1.56-6.24) European COVID-19 patients [32]. In fact, analysis adjusted for age and comorbidities shows that frailty is the strongest predictor for mortality in COVID-19 patients aged $>65$ years [69].

\section{Pathophysiological Alterations Underlying Sarcopenia}

The mechanism of muscle wasting is rather complex. Sarcopenia has a multidimensional pathophysiology that reiterates all of the biologic cornerstones of aging including inflammation, oxidative stress, metabolic dysregulation, malnutrition, hormonal alterations, etc. (Figure 3) $[14,17,80]$. All these factors exacerbate immune functioning in older adults and increase their risk for COVID-19. This section elaborates on factors underlying changes in the structure and force-generating capacity of skeletal muscle in old age in detail. 

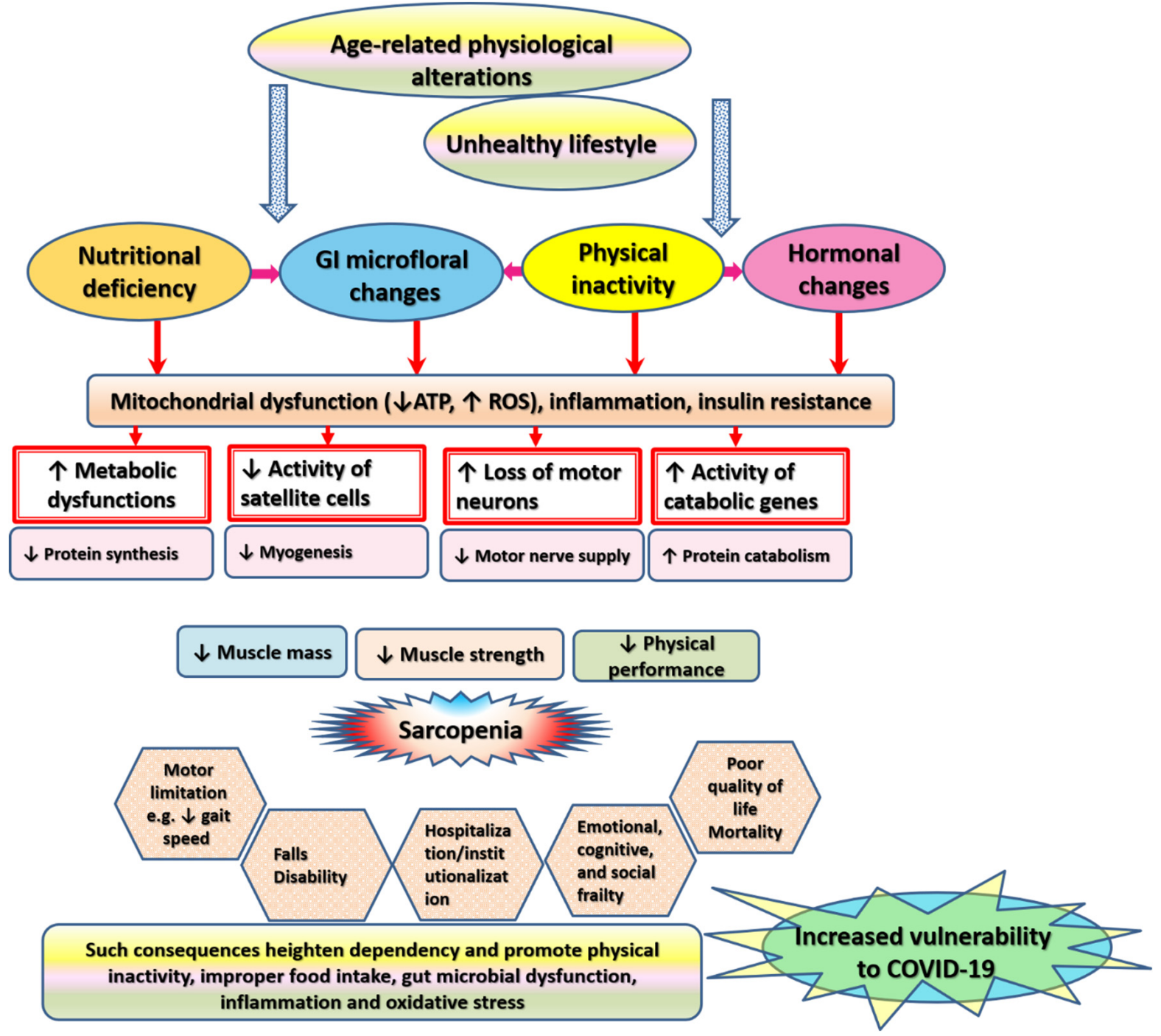

Figure 3. Schematic summary of possible factors contributing to the development of sarcopenia and COVID-19 in older adults. Abbreviations: $\uparrow$ denotes increase, $\downarrow$ denotes decrease, COVID-19: Coronavirus Disease 2019, GI: gastrointestinal, ATP: adenosine tri-phosphate, ROS: reactive oxygen species. Multiple factors contribute to sarcopenia in older seniors. The elderly experience malnutrition due to decreased food (protein) intake associated with poor dentation and sensory alterations, which commonly develop during old age. Unhealthy lifestyles, which entail the intake of improper diets (e.g., high-fat/low-fiber diets) and physical inactivity, induce serious changes in gut microflora composition. The propagation of gut pathogens results in local inflammation in the gut and intestinal permeability, which promote the passage of endobacterial toxins into the systemic circulation. Moreover, the levels of multiple anabolic hormones change with aging (e.g., testosterone and growth hormones decrease). These factors promote a persistent state of chronic low-grade inflammation along with multiple age-related morphological, structural, and functional alterations in the mitochondria leading to deficient energy production (ATP) and increased emission of free radicals (oxidative stress). Both free radicals and inflammatory cytokines alter cellular signaling that regulate metabolism and energy production resulting in anabolic resistance, increased muscle protein turnover and posttranslational modifications in favor of catabolism, decreased number and size of myofibers, and diminished response of satellite stem cells to injury. All these effects lead to loss of muscle mass and strength as well as poor muscular performance, which are common in sarcopenia. In addition to motor impairments, which decrease gait speed and increase the risk for fall, sarcopenia leads to other debilitating consequences such as cognitive and emotional frailty, hospitalization and/or institutionalization, rehospitalization, lower quality of life, heightened disability, and mortality. Both sarcopenia and its adverse effects promote a vicious cycle of physical inactivity, nutritional deficiencies, gut microbial dysfunction, which all fuel inflammation and oxidative stress, putting these patients at a high risk for COVID-19. 


\subsection{Inflammation}

The terms inflammaging and/or immunosenescence describe age-related immune dysregulations that involve a maladaptive increase of basal inflammatory responses. Chronic subclinical systemic inflammation is a main cause of accelerated aging, including skeletal muscle wasting and fatigue in old age and in chronic disorders $[17,81,82]$. Inflammatory cytokines (e.g., TNF- $\alpha$, interleukin (IL)- $1 \beta$, IL-6, and interferon- $\gamma$ ) induce muscle wasting directly by enhancing protein degradation and catabolism or indirectly by promoting anabolic resistance via blockage of the expression and activity of hormones involved in metabolism such as growth hormone and IGF-I $[14,17]$. Cytokines promote apoptosis of muscle cells as well as of fibroblasts and endothelial cells, which exist inside and affect the muscular microenvironment. Signaling associated with increased systemic cytokines and their soluble receptors in the circulation induces oxidative stress and mitochondrial dysfunction in addition to disrupting cellular homeostasis, metabolism, muscle proteostasis, myogenesis, muscle growth, and remodeling [12].

Inflammatory signatures in sarcopenic elders entail elevation of P-selectin, c-reactive protein (CRP), and interferon $\gamma$-induced protein 10 as well as reduction of myeloperoxidase (MPO), IL-8, monocyte chemotactic protein 1 (MCP-1), macrophage inflammatory protein 1$\alpha($ MIP-1 $\alpha)$, platelet-derived growth factor (PDGF) BB [12,83]. In addition, gender-specific inflammatory fingerprints of sarcopenia have been identified $[12,82,83]$. Sarcopenic women demonstrate higher levels of CRP, P-selectin, and MIP-1 $\beta$ and decreased levels of MPO, IL-8, MCP-1, PDGF-BB, MIP- $1 \alpha$, and eotaxin. On the other hand, sarcopenic men exhibit elevated CRP and lower levels of interferon- $\gamma$, FGF b, IL-17, TNF- $\alpha$, MIP1- $\beta$ compared with non-sarcopenic matched control [83]. A recent meta-analytic review reports higher levels of IL-6 in men with a good muscle condition (indicated by grip strength) than in women with muscle wasting [82]. IL-6, known as the cytokine for gerontologists, expresses a dual effect in skeletal muscle. On one hand, muscular IL-6, which is released following muscular activity (e.g., after exercise) is considered a myokine that plays an anti-inflammatory or regenerative role. Its related response involves inhibiting the release of TNF- $\alpha$ and IL-1 $\beta$ and enhancing the synthesis of their receptors. Nonetheless, persistently active individuals display low serum levels of IL-6. On the other hand, systemic IL-6 is pro-inflammatory. It hinders anabolic signaling pathways such as IGF-1 and promotes gluconeogenesis and lipolysis $[17,82]$. Muscle involvement in gluconeogenesis results in a considerable loss of muscle mass due to excessive breakdown of muscle proteins in order to use amino acids for ATP production [38].

Given the role of chronic low-grade inflammation in muscle wasting, researchers are investigating therapeutic agents that target specific cytokines, their receptors, or downstream intracellular signaling $[12,84]$. For example, non-steroidal anti-inflammatory drugs block prostaglandin biosynthesis and inflammatory responses by suppressing the activity of cyclooxygenase [12]. Nevertheless, the therapeutic efficacy of these agents is insufficient to suppress muscle inflammation, and considerable side effects ensue [84].

\subsection{Oxidative Stress}

Mitochondria are the main hub for cellular metabolic and oxidative homeostasis [85]. Aging is associated with mitochondrial dysfunction, which results from alterations in mitochondrial morphology, inner contents, and activity of the complexes of the electron transport chain secondary to DNA mutations, deletions, or damage [5,11,86-88]. Skeletal muscle uses large amounts of oxygen to perform its activities, it produces high quantities of reactive oxygen species (ROS). Under natural physiological conditions, the antioxidant system degrades ROS [5]. However, senescent mitochondria fail to fulfil their energy producing role, and they generate huge amounts of ROS. In the meantime, aged muscle cells fail to remove and/or replace dysfunctional mitochondria [5,11,86-88].

A wealth of research has clearly shown that ROS is remarkably high in aged muscle while the development of a chronic state of low-grade inflammation in the elderly primarily results from an imbalance in intracellular redox. On one hand, ROS activates NF- $\mathrm{kB}$ in 
skeletal muscle by acting as a secondary messenger for TNF- $\alpha[14,80]$. On the other hand, ROS production in skeletal muscle undergoing inflammation is persistently high. This is mainly attributed to the activity of TNF- $\alpha$. Both ROS and TNF- $\alpha$ stimulate the production of a pro-oxidant named myostatin (also known as growth differentiation factor-8, GDF-8), a member of the TGF- $\beta$ family, in skeletal muscle cells via NF- $\kappa B$ and nicotinamide adenine dinucleotide phosphate hydrogen (NADPH) oxidase-dependent signaling [12,80].

Myostatin is a primary effector in the development of sarcopenia: it prevents the growth of skeletal muscle by hindering myoblast proliferation and myogenic differentiation as well as by fostering muscle protein degradation $[12,89]$. When myostatin binds to activin type IIB receptor (ActR2B), Smad2 and Smad3 phosphorylate forming a heterodimer with Smad4. Then, they translocate into the nucleus to upregulate genes that inhibit IGF1/Protein kinase B (AKT)/mammalian target of rapamycin (mTOR) signaling — a primary pathway that stimulates protein synthesis [12,59]. Hence, skeletal muscle endures a vicious cycle of oxidative stress and inflammation, which results from an ongoing cross talk between TNF- $\alpha$, ROS, and myostatin [80]. Evidence points that myostatin-null muscle cells, which are resistant to wasting, demonstrate remarkably high levels of basal antioxidant enzymes and low levels of NF-KB and ROS [80]. Similarly, blocking myostatin antibody is reported to decrease insulin resistance and increase the size and number of skeletal muscle fibers resulting in increased muscle mass in young mice and mitigation of sarcopenia in aged mice $[14,89,90]$. Accordingly, antihypertrophic myostatin is considered a potential therapeutic target in muscle wasting [12,90]. High baseline levels of oxidative stress in aging and comorbid conditions (e.g., diabetes, obesity, and cardiovascular disorders) increase the liability to COVID-19 and pave the way for poor disease prognosis [91].

\subsection{Metabolic Alterations}

Muscle contraction is a complex process, which is run by a highly energy-demanding molecular machinery that comprises ionic channels/pumps, signaling molecules (e.g., proteins), electro-mechanical couplers, and contractile structures (e.g., myosin and actinfibrillar proteins that constitute the thick and thin filaments, respectively) $[38,88]$. Excessive levels of ATP are necessary for excitation-contraction coupling, which involves the release of calcium $\left(\mathrm{Ca}^{2+}\right)$ from the sarcoplasmic reticulum upon depolarization of the sarcolemma (the muscle surface membrane) during the contraction phase. Likewise, ATP is needed to end muscle contraction by terminating the filament interactions through pumping $\mathrm{Ca}^{2+}$ out of the sarcoplasma back into the extracellular space and sarcoplasmic reticulum [88].

Mitochondria form anisotropic networks in skeletal muscle. Through oxidative phosphorylation, they supply muscle cells with ATP to promote muscle contraction [37]. ATP levels remarkably drop with aging not only because protein activity declines but also because the number of mitochondrial oxidative enzymes decreases, which seriously alters mitochondrial protein synthesis and maximum oxygen uptake [15]. Declines in mitochondrial biogenesis and redox metabolism trigger skeletal muscle proteolysis by inducing severe dysregulations in skeletal muscle energy metabolism. Evidence notes that disrupted skeletal muscle bioenergetics precede the onset of muscle mass loss [38,92].

Skeletal muscle is the largest endocrine organ, and it plays a crucial role in metabolism by contributing to $75 \%$ of glucose uptake $[37,88]$. Skeletal muscle bioenergetics are regulated by numerous "fuel gauge" signaling pathways that detect changes in cellular energy status. In order to fuel energy consuming processes such as muscle contraction, mitochondrial ATP production from intermediary substrates is triggered by signaling cascades associated with adenosine monophosphate activated protein kinase (AMPK), the pyridine nucleotide nicotinamide adenine dinucleotide (NAD+)-dependent deacetylase SIRT1, and peroxisome proliferator-activated receptor- $\gamma$ coactivator- $1 \alpha$ (PGC-1 $\alpha)$ [37,88]. For example upregulation of AMPK, along with activation of carnitine:palmitoyl transferase-1 (CPT-1) in skeletal muscle, catalyzes the rate-limiting step for oxidation of the long chain fatty acetyl-CoA inside the mitochondria [93]. The underlying mechanism entails regulating the activity of key metabolic targets such as glucose transporter 4 (GLUT4), cyclic adenosine 
mono phosphate response element binding protein (CREB), and nuclear respiratory factors (NRFs e.g., NRF2), which finetune cellular adjustment to energetic stress by modulating the expression of a complex network of metabolic genes including those entangled in autophagy, antioxidant production, mitochondrial biogenesis, and mitochondrial energy production $[37,88,94]$. Aged skeletal muscle fails to fulfil its metabolic role mainly because of insulin resistance, which increases with aging $[12,15,37,38,60,80]$.

Skeletal muscle insulin resistance is an outcome of dysfunctional insulin signaling and diminished activity of glucose transport, which originate from intrinsic epigenetic or genetic defects in the metabolic program or from exposure to high levels of proinflammatory cytokines, insulin, glucose, or free fatty acids [56,95]. DNA methylation, a covalent addition of a methyl group to cytosine bases in a CpG dinucleotides, is the most common form of translational modifications underlying age-related epigenetic changes in skeletal muscle genes. DNA methylation does not change DNA sequence of affected genes, but it disrupts gene function and expression, especially when it occurs within a promoter or enhancer region $[18,96]$. Researchers identified an age-specific expression signature of sarcopenia comprising 45 genes (involving upregulation of 27 genes e.g., C1QA, Galectin-1, C/EBP-beta, and FOXO3A and downregulation of 18 genes e.g., glutamine transporter SLC38A1, a TRAF-6 inhibitory zinc finger protein, and membrane-bound transcription factor protease $S 2 P)$, which can efficiently distinguish type II fibers in the vastus lateralis muscle in old men from young men [97].

Examination of the epigenetic profile of human type I and type II skeletal muscle fibers allowed Begue and colleagues to detect 143,160 differentially methylated (largely hypomethylated) CpG sites across 14,046 genes indicating fiber type-specific methylation [98]. Moreover, array-based approach and pathway analysis have revealed sex differences in 40 genes in myoblasts (e.g., LAMP2 and SIRT1) and 9 genes in myotubes (e.g., KDM6A) in both DNA methylation and gene expression among women compared with control men cross-matched based on age and BMI. These differences were detected in vitro on autosomal chromosomes and X-chromosome, in spite of absence of factors that differ between sexes such as sex hormones [99]. Of interest, age-related DNA methylation in skeletal muscle largely alters the expression of core genes that regulate energy metabolism as well as inflammatory and oxidative phosphorylation such as NADH:Ubiquinone Oxidoreductase Subunit B6 (NDUFB6) and Cytochrome C Oxidase Subunit 7A1 (COX7A1), which code for components of the respiratory chain $[18,97,99]$. Environmental factors such as high carbohydrate intake and exposure to insulin (which is equivalent to insulin resistance in type 2 diabetes) acutely induce epigenetic changes in skeletal muscle by altering DNA methylation profile: decreasing DNA methylation in the $C a^{2}+$ pump ATP2A3 gene and increasing DNA methylation in the gene body of death-associated protein kinase 3 (DAPK3), a gene that regulates cell proliferation, apoptosis, and autophagy [95].

Type II muscle fibers mobilize ATP and create tension more readily than slow fibers. Therefore, age-related muscle fiber transformation embroiling loss of the contractile tissue increases oxidative metabolism in fast fibers relative to glycolytic metabolism-a shift that remarkably impedes glucose uptake from the circulation by inducing insulin resistance $[37,38,88]$. Glucose dysregulation in skeletal muscle also results from the effect of increased fat and ceramide infiltration as well as chronically elevated levels of ROS and inflammatory cytokines. All these factors potentiate UPS and alter IGF-1 resulting in insulin resistance and anabolic resistance $[12,15,60,80]$. Insulin resistance blunts glucose supply to body tissues leading to a state of energy deficit. As such, gluconeogenesis through protein catabolism increases in order to meet increased body demand for energy [33,34]. Directing amino acids stored in muscle proteins toward energy production disrupts the balance between muscular protein synthesis and degradation in favor of degradation, eventually leading to muscle mass loss [37]. Based on the available literature, researchers have identified sex-specific biomarkers of metabolism and skeletal muscle that are associated with age-related changes in gait speed and cognitive functioning. For instance, normal gait speed and cognition in women are associated with low lactate dehydrogenase (LDH) and 
higher levels of leptin, insulin, and percentage of body fat. On the other side, men with higher levels of cholesterol and higher ASM express less decline in muscle strength whereas greater alterations in gait speed are associated with low creatinine and high IGF-1 [100].

\subsection{Glycation Stress}

Old age, smoking, and unhealthy diets accelerate inflammaging. On one hand, these conditions promote enzymatic binding of glycans (carbohydrate molecules such as sialic acid, mannose and fucose) to proteins and lipids on the cell surface or in the blood stream resulting in impairments in the pro- and anti-inflammatory properties of immunoglobulins [81,101]. In addition, glycation is another biochemical process that contributes to muscle dysfunctions occurring in sarcopenia, and it increases incidental falls among old people $[13,34,75]$. It involves the buildup of highly toxic substances known as advanced glycation end products (AGEs) through a non-enzymatic reaction (known as Maillard's reaction), which embroils the binding of reducing sugars (e.g., glucose) with free amino groups of proteins under the effect of heat $[70,102]$. This reaction results in the formation of Schiff bases, which undergo a series of irreversible reactions resulting in the formation of more stable ketoamines. Ketoamines further change into dicarbonyls, intermediates of AGEs [102].

Chronic overproduction of AGES - occurring with aging as well as in metabolic (hyperglycemic), genetic, and inflammatory conditions-causes myopathy and accelerates muscle wasting $[33,34,102]$. Experimental evidence reveals inhibition of myotubes formation and accumulation of $\mathrm{N} \varepsilon$-carboxymethyl-lysine in $\mathrm{C} 2 \mathrm{C} 12$ skeletal muscle cells treated with glucose-induced AGEs $(0.1 \mathrm{mg} / \mathrm{mL})$ [103]. High blood or skin levels of AGEs correlate with muscle fatigability and reductions in muscle mass, grip strength, and glucose tolerance in the elderly as well as in children and young adults with type 1 diabetes: pointing that the negative effects of glycation stress on skeletal muscle function occur early regardless of age [34].

Reverse phase protein array analysis shows that AGEs impair cellular signal transduction pathways by increasing phosphorylation at 8 phosphorylation sites and blocking phosphorylation at 64 phosphorylation sites in skeletal muscle [103]. This molecular effect results when AGEs bind their main receptor, the Receptor for Advanced Glycation End products (RAGE). RAGE is a multiligand receptor. RAGE density on the cell surface and availability of its ligands influences its effects on various cellular signaling pathways [33]. Proper levels of RAGE contribute to myogenesis/muscle regeneration during development and after acute injuries by enhancing the proliferation and differentiation of myosatellite stem cells and by regulating myoblast trophism [33,34]. Conversely, persistently high levels of AGEs entail constant activation of RAGE, which in turn activates TLR4 in macrophages and upregulates Mitogen-activated protein kinase (MAPK). MAPK activates the inflammatory signal transducer and activator of transcription 3 (STAT3) Tyr 705 and NF- $\mathrm{kB}$ resulting in continuous production of TNF $\alpha$, IL-6, IL-1 $\beta[34,103,104]$.

Chronic production of inflammatory mediators causes serious cellular damages by modifying normal properties and functions of proteins and modulating signaling pathways conducive to oxidative stress leading to heightened stress of endoplasmic reticulum (ER) and activation of mitochondria-related cell death signal transduction [34,103]. AGEs-related ER stress is associated with increased insulin resistance and downregulation of extracellular signal-regulated kinase (ERK) $\mathrm{Thr}_{202} / \mathrm{Tyr}_{204}$ and all phosphorylation sites related to IGF-1 signaling including skeletal muscle GLUT4 (Scl2a4 gene), a principal regulator of glucose homeostasis $[103,105]$. Thus, AGEs cause neurodegeneration of motor neurons and changes in muscle fiber, which are key factors in muscle mass loss, by triggering inflammation, oxidative stress, and insulin resistance [102,105]. Therefore, suppressing the production of AGEs and blocking their associated inflammatory, oxidative, and metabolic responses can be a target of preventing muscle dysfunction in old age [34]. 


\subsection{Physical Inactivity}

Physical activity is a key factor that affects physiological processes within the entire body including those involved in maintaining the shape and structure of muscle fibers $[36,106]$. Evidence denotes that biological aging of human skeletal muscle is not necessarily related to chronological aging-loss of muscle mass can start as early as the second decade of life, and it is exacerbated by muscle inactivity associated with a sedentary lifestyle $[2,3,15]$. Oxidative stress is a main inactivity-related genotoxic stressor. Free radicals stimulate mitochondrial dysfunction and vice versa leading to cellular aging and alteration of the architecture of myofibers, which is associated with shortening of telomeres (terminal sequences of TTAGGG repeats, which represent an aging marker that is linked to physical inactivity) $[3,107]$.

Immobility, skeletal muscle disuse, or sedentary lifestyle contribute to muscle wasting via multiple mechanisms that involve inducing inflammation and metabolic dysfunction as well as altering the composition of gut microbiome community $[48,108,109]$. In this regard, genome-wide transcriptional analysis of muscle biopsy samples obtained from people on short-term muscle disuse (bed rest for 5 days) revealed that physical inactivity induced skeletal muscle insulin resistance and altered muscle gene expression in a pattern associated with reduced lipid oxidation and capacity for triglyceride export $(A P O B)$, increased lipogenesis (i.e., PFKFB3, FASN), and increased amino acid export (SLC43A1) [109]. Physical inactivity alters the activity of the main anabolism-regulating molecule AKT. AKT maintains muscle mass and strength via its dual action, which involves modulating mTORC1 to increase protein synthesis as well as suppressing Forkhead Box O transcription factor (FOXO) to inhibit protein degradation. Downregulation of AKT and IGF-1 associated with skeletal muscle disuse gives rise to inflammatory cytokines and molecules involved in muscle breakdown such as MuRF1 and muscle atrophy F-box (MAFbx) [73]. Meanwhile, refeeding attempts through the use of amino acids fail to counteract anabolic resistance (i.e., increase protein synthesis) under conditions of low physical activity $[48,110]$. On the contrary, exercise promotes the expression of PGC- $1 \alpha$ [111], a core transcription factor involved in metabolic control within skeletal muscle. In addition to mediating mitochondrial biogenesis, PGC- $1 \alpha$ also modulates the activity of GLUT4, CREB, and NRFs, which encrypt metabolic genes involved in the control of glucose metabolism and lipid uptake/oxidation $[37,94,111]$. Altogether, these reports suggest that physical inactivity contributes to muscle mass loss by altering mitochondrial and metabolic activities in skeletal muscle.

Engaging in proper exercise activity (moderate to vigorous levels) counteracts destructive effects of inactivity, restores muscle mass, and prevents the development of sarcopenia in older individuals [106,112]. As such, the World Health Organization recommends performing regular physical exercise throughout one's life [106]. Exercise is an energetic stressor that operates in a manner similar to caloric restriction: it restores and corrects metabolism in skeletal muscle by modulating metabolic-sensing pathways [88,92]. Exercise corrects anabolic resistance and improves insulin sensitivity resulting in an increase in the differentiation and proliferation of satellite cells, mitochondrial metabolic efficiency and homeostasis. As a result, ATP is sufficiently produced to promote the contraction/relaxation of muscle fibers without altering physiological redox, muscle capillarity, oxygen delivery, and innervation $[46,88,106]$.

Physical activity can reserve muscle mass by reshaping the structure of resident gut microbiome $[113,114]$. A comparison between sedentary women and women performing the least degree of exercise recommended by the World Health Organization revealed significant differences in 11 gut genera between both groups as examined by high-throughput sequencing of the 16s rRNA gene. Active women expressed higher abundance of healthpromoting bacterial populations such as Faecalibacterium prausnitzii, Roseburia hominis and Akkermansia muciniphila. Various bacterial species correlated with physical activity and key indices of body composition such as body fat percentage and muscle mass [108]. Similarly, rugby athletes demonstrated remarkably higher diversity of gut microbiome involving 
22 distinct phyla with lower abundance of Bacteroides and Lactobacillus species compared with sedentary controls. Markers of physical activity (plasma CK), inflammation, and metabolism varied significantly between both groups [115]. Moreover, metabolic phenotyping and functional metagenomic analysis revealed that relative to sedentary controls, professional rugby athletes exhibited increased microbial species involved in carbohydrate metabolism, biosynthesis of amino acids and antibiotics as well as numerous microbial metabolites such as short-chain fatty acids, acetate, propionate, and butyrate. Gut microbiome structure correlated with muscle turnover/fitness and overall health in professional athletes compared with sedentary control groups [114]. In other words, physical activity can promote muscle function by supporting nutritive microbial populations that supply the host with nutrients essential for integrated physiological functioning. Nonetheless, the effects of physical in/activity on gut microbiome are reversible, and they vary considerably according to several factors such as BMI and diet composition [113,116]. For more details on the effect of gut microbiome on skeletal muscle see Section 6.10.

\subsection{Neuromuscular Failure}

Motor disability demonstrated by aged people is related to lowered cognitive performance, atrophic changes of the central nervous system (CNS), peripheral nerve dysfunction, and impairments of the neuromuscular junction structure and function [2,117]. Evidence denotes a role of dopaminergic dysfunction-related neurodegenerative pathology in sarcopenia $[8,118,119]$. It involves the accumulation of $\alpha$-synuclein and the formation of Lewy bodies in dopaminergic neurons same as in Parkinson's disease. As a result, progressive loss of dopaminergic neurons occurs in the substantia nigra pars compacta [120], which results in motor symptoms [117,121].

Sarcopenia is a multifactorial neuromuscular syndrome characterized by muscle cell senescence deriving from neuromuscular denervation [86]. Reduced muscle contraction occurs with aging as a result of irreversible neuron loss (including motor neurons) and reduction of the number of alpha motor units from the spinal cord [5]. A motor unit consists of a cell body in the ventral horn of the spinal cord, the alpha motor neuron, and muscle fibers that it innervates [39]. Ontology analysis indicates that age-related intragenic methylation changes interfere with pathways related to muscle cell and axon guidance signaling resulting in neuromuscular denervation [18]. Reinnervation or motor unit remodeling is a process employed by denervated muscle fibers to compensate for the functional declines that follow denervation processes. It involves increasing the production of specific proteins and chemotactic signals by denervated fibers, which lead to expansion of residual motor units $[5,12]$. However, the reinnervation process severely deteriorates or completely fails as age advances $[6,86]$. Mitochondrial dysfunction is a major contributor to neuromuscular pathogenesis [2,122]. The efficiency of oxidative phosphorylation and ATP production declines with aging due to mitochondrial senescence, failure to proliferate, impaired respiratory function, instability/permeability of the internal mitochondrial membrane, and increased ROS production $[37,86,87]$. The latter seriously damages neuromuscular structures [37], and disrupts events associated with cross-bridge cycling [5,12]. Particularly, it affects the synthesis of myosin heavy chain proteins, which steeply decline with aging due to reduced protein synthesis and accelerated protein breakdown [15].

Motor neurons and muscle fibers are abundant in mitochondria especially on the sides and the motor end plate of the neuromuscular junction (NMJ) $[37,86]$. NMJ is a synapse between motor neurons and skeletal muscle cells that controls locomotion. It consists of motor nerve terminal, synaptic basal lamina, postsynaptic muscle fiber, and muscle membrane [5,122]. NMJ is highly vulnerable to various age-related mitochondrial alterations [86,87]. Oxidative stress and apoptotic signaling correlating with altered mitochondria seriously threaten NMJ integrity by promoting motor end plate fragmentation and by damaging Schwann cells, which surround the terminals of motor neurons at the NMJ $[5,86]$. NMJ deficiency provokes impairments in neurotransmission and signaling cascades that regulate cell size and excitation-contraction coupling [12,86,87]. Failure of 
the sarcolemma to generate an action potential is mediated by ROS, which alters the release of acetylcholine at the synaptic cleft [5]. Research highlights a role of mitochondrial CHCHD10 protein, which is highly expressed at NMJ post-synapse, in ATP generating capacity in skeletal muscle-which is associated with enhanced neurotransmission via upregulation of acetylcholine receptors (AChRs) and acceleration of agrin-induced AChR clustering [122]. Deficiency or dysregulation of CHCHD10 leads to NMJ fragmentation, altered neurotransmission, and loss of motor neurons [87].

Defective $\mathrm{Ca}^{2+}$ homeostasis plays a core role in muscle wasting and loss of muscle strength and function in old age [123]. $\mathrm{Ca}^{2+}$ is a second messenger that plays a key role in numerous neuronal activities e.g., synaptic plasticity and membrane excitability $[70,124]$. Impairment of the release and reuptake of $\mathrm{Ca}^{2+}$ from the sarcoplasmic reticulum is a major reason for the decline in force generation exhibited by aged type II muscle fibers [5,12]. The underlying mechanism involves a significant drop in the amount of $\mathrm{Ca}^{2+}$ required for the initiation of muscle contraction due to uncoupling of the signal required for $\mathrm{Ca}^{2+}$ release leading to delayed $\mathrm{Ca}^{2+}$ peak concentration. In addition, the turnover rate of $\mathrm{Ca}^{2+}$-ATPase in aged muscle cells is slow, which makes it vulnerable to oxidative damage [5,15]. Higher levels of circulating skeletal muscle-specific troponin $\mathrm{T}$, which regulates $\mathrm{Ca}^{2+}$ mediated excitation-contraction coupling, characterize contractile insufficiency of skeletal muscle [17]. In other words, the number of activated muscle fibers as well as motor coordination decline due to heightened irregularity of muscle unit firing and loss of motor units [15]. In the meantime, $\mathrm{Ca}^{2+}$ channel blockers can improve self-pace walk and stance times in hypertensive older patients [12].

\subsection{Hormonal Dysregulations}

Multiple hormones directly affect skeletal muscle metabolism, muscle mass, and function $[5,44,57]$. Sex steroids (estrogen and testosterone) decline with aging contributing to various age-related pathologies including muscle wasting $[12,15,57,125]$. Of interest, androgens such as testosterone block the production of myostatin and ROS, inhibit apoptosis, potentiate the regenerative potential of myosatellite stem cells, accelerate muscle IGF-1 expression, regulate skeletal muscle metabolism, and increase muscle protein synthesis rate and muscle mass in elderly men and aged rodents [12,126,127]. Mechanistically, testosterone activates $\mathrm{AKT} / \mathrm{mTORC} 1$ and inhibits FOXO through none-genomic action e.g., perturbations in cyclic nucleotide production, $\mathrm{Ca}^{2+}$ fluxes, and kinase activation or through a genomic action by binding the cytosolic androgen receptor to promote its translocation to the nucleus leading to the expression of target genes [12]. Testosterone treatment is associated with serious adverse effects in the elderly such as prostate cancer. Moreover, its effects on skeletal muscle take a relatively long time to develop, and they vanish following treatment discontinuation $[12,127]$.

Age-related increase of visceral fat and declines in LBM and bone mineral density speak for the metabolic dysregulations that result from drops in growth hormone $(\mathrm{GH})$, which demonstrates lipolytic effects, along with elevated cortisol [5,15]. Growth hormone replacement effectively increases muscle mass in aged subjects, but it does not enhance muscle performance [44]. Insulin is another primarily important hormone. It affects every single cell in the body, and its signaling pathway, IGF-1, interacts with and regulates a plethora of other signaling cascades that regulate metabolism $[56,125]$. Oxidative stress and chronic inflammation that develop with aging block IGF-1 and promote insulin resistance giving rise to anabolic resistance, catabolism, adipose infiltration in skeletal muscle, and increased onset of type 2 diabetes. All these events endanger muscle functionality [12,17,46,59,82,89].

\subsection{Nutritional Deficiency}

Protein-energy malnutrition is one of the main risk factors for skeletal muscle loss [128]. The co-occurrence of malnutrition and sarcopenia in older adults is high [17,49]. Elderly people in health care settings experience a higher prevalence of malnutrition and sarcopenia than their community-dwelling counterparts [7]. In one study, the prevalence of 
sarcopenia, cachexia, and frailty in malnourished geriatric patients was $93 \%, 80 \%$, and $53 \%$, respectively [49]. Moreover, malnutrition increases with prolonged hospitalization due to immobility, inflammation, etc. On the other hand, malnutrition can exacerbate overall health and skeletal muscle by severely compromising immune functioning [77].

Malnutrition and associated sarcopenia in older individuals increase with advanced age, polypharmacy, and institutionalization [47]. Their main trigger is decreased energy intake, which occurs due to a variety of age-related physiologic alterations such as anorexia or loss of appetite, poor dentition or chewing, swallowing problems, impaired sense of taste and smell, slower gastric emptying and constipation, hormonal alterations, eating dependencies, poor physical and mental health, as well as social and economic difficulties $[7,15,41,47]$.

Among all nutrients, proteins play a chief role in muscle mass maintenance by enhancing the anabolic response of skeletal muscle $[129,130]$. Despite the fact that older people need more protein than younger groups, a considerable proportion of institutionalized and community-dwelling elders do not receive the minimum daily protein requirements $(0.8 \mathrm{~g} / \mathrm{kg}$ body weight/day). In addition, multiple factors may impede the anabolic effect of dietary proteins such as GI-related physiological changes (a common feature of aging), physical inactivity, obesity, and insulin resistance $[110,131]$. Apart from problems associated with protein absorption, the literature reports insufficiency of the globally recommended amount of protein to prevent muscle wasting in older adults $[15,41,132]$.

The dynamic of muscle mass loss in old age is quite complex. While insulin resistance triggers protein catabolism in skeletal muscle $[15,75]$, chronically low protein intake severely impair tissue nitrogen balance, protein content, and the balance between muscle protein synthesis and degradation in old age resulting in muscle wasting [41,133]. Furthermore, protein-deficiency malnutrition induces and exacerbates numerous age-related physiological alterations that affect the structure and function of skeletal muscle such as protein metabolism and immune response [133]. Unhealthy diets (e.g., high fat diet) promote systemic inflammation by triggering gut dysbiosis while lipid molecules directly activate signaling involved in oxidative stress and inflammation [134].

The development of sarcopenia is a long-term process. Hence, even small and slow alterations in the balance of muscle proteins affect muscle composition and function if they persist over years [15]. Vitamin D is another key nutrient involved in muscle functioning [135]. Hypovitaminosis D prevails in $50.4 \%$ of older adults, and longitudinal data show that elders with vitamin D levels less than $30 \mathrm{ng} / \mathrm{mL}$ express poor muscle function and high risk for general mortality [136]. Evidence associates the lowest serum levels of calcitriol, the biologically active form of vitamin $\mathrm{D}$, also known as 1,25-dihydroxyvitamin $\mathrm{D}(1,25(\mathrm{OH}) \mathrm{D})$, with high fat mass, low SMI, and muscle-related metabolic dysfunction (high insulin resistance) compared with the highest serum 1,25(OH)D in relatively healthy community-dwelling seniors [137]. Vitamin D deficiency in old people results from less dietary intake of foods rich in vitamin $\mathrm{D}$ and from less exposure to sun rays necessary for the internal synthesis of $1,25(\mathrm{OH}) \mathrm{D}$ [135].

Given that malnutrition is a key risk factor for frailty, screening for malnutrition in old people and in symptomatic COVID-19 patients may facilitate the identification of people at risk for muscle failure $[7,17,23,49,128]$. Details of nutritional screening are reported elsewhere [23]. Several nutritional interventions are reported to prevent or revert sarcopenia and related muscle fatigue. High protein diets are of particular importance; healthy active individuals require, at least, $1.0-1.2 \mathrm{~g}$ of protein $/ \mathrm{kg}$ body weight/day while the need for protein in sarcopenic individuals is even greater $(1.2-1.5 \mathrm{~g} / \mathrm{kg}$ body weight/day) $[41,46,138]$. Older individuals are resistant to refeeding i.e., recovering their nutritional deficiency is slower and more difficult than in younger ages [133]. Moreover, muscle anabolism in the elderly depends not only on the amount of protein consumed but also on its quality as determined by its source and speed of its rate of absorption $[129,130]$. Evidence reveals increased fractional synthesis rate of myosin, a motor protein that contributes to muscle contraction, in older adults receiving high protein diet. Meanwhile, 
adequate protein diet had no effect on myosin synthesis except when it contained soluble milk proteins. On the other hand, fractional synthesis rate of mitochondrial muscle protein increased only in the elderly consuming soluble milk proteins irrespective of the consumed protein quantity [129]. Fermenting milk with bee honey increases milk content of proteins and health-promoting metabolites of lactic acid bacteria such as antioxidants. In addition, phenols from bee products can promote skeletal supply of amino acids [75,139].

The consumption of low glycemic index foods is of particular importance in order to prevent and/or control anabolic resistance that results from age-related glycemic dysregulation $[56,140,141]$. Low glycemic index foods (e.g., full grains, bran of wheat and rice, and soy) are rich in complex unrefined carbohydrates, which release glucose slowly [140,142]. In addition, the fiber contents in such foods benefit glycemic control by enhancing healthy gut microbial fermentation. This process results in the production of several nutrients (e.g., acetate, propionate, and butyrate), which support protein delivery to skeletal muscle through a mechanism that involves activation of G-protein-coupled receptors (GPRs) such as GPR41 and GPR43. GPRs stimulate the intestinal epithelial L-cells to release gut hormones (glucagon-like peptide 1 -GLP-1, and peptide YY -PYY). They also trigger the secretion of leptin by adipocytes resulting in appetite decrease and increased insulin sensitivity [56].

Other dietary elements that can slow sarcopenia include creatine-rich food (e.g., fish and meat), glutamic acid-rich food (e.g., soy and egg), tryptophan-rich food (e.g., milk and peanuts), long-chain polyunsaturated fatty acids (e.g., fish oil), vitamin $\mathrm{D}$, and antioxidant supplements (e.g., selenium, vitamin A, vitamin C, vitamin E, and $\beta$-carotene) $[41,46,138]$. However, purified antioxidant supplements may become pro-oxidants when they overactivate the NRF2/antioxidant response element (ARE) antioxidant system, which is associated with serious adverse effects including cancer and mortality $[5,143]$.

As for vitamin $\mathrm{D}$, supplementing pre-sarcopenic elders deficient in vitamin $\mathrm{D}$ with three weekly doses of cholecalciferol (vitamin D3, 10,000 IU) for 6 months significantly improved ASM but had no effect on grip strength. Notably, obesity attenuated muscular response to cholecalciferol [144]. Another study shows that a combination of the same dose of cholecalciferol (5 days/week/13 weeks) and treadmill aerobic training during week 13 significantly decreased intramyocellular lipid in the gastrocnemius muscle and increased tissue-level $\mathrm{VO}_{2}$ in healthy older adults. Of interest, neither cholecalciferol nor aerobic training alone could affect the levels of intramyocellular lipid [145]. A recent review shows that vitamin D supplementation in old age implies numerous health benefits including sarcopenia amelioration, cognition enhancement, depression treatment, cancer prevention, and reduction of mortality [146]. It is important to note that routine supplementation of vitamin $\mathrm{D}$ should be in the form of cholecalciferol rather than ergocalciferol since benefits are only documented for cholecalciferol. In addition, no contraindications exist for daily oral cholecalciferol of 800 to 1000 IU to all individuals aged $\geq 65$ years who do not have a contraindication, and screening or monitoring are not required because cholecalciferol has a minimal risk in this population [146].

\subsection{Satellite Cells Senescence}

Skeletal muscle cell senescence involves progressive damages in many biological cellular settings that result in cell-cycle arrest [147]. Satellite stem cells (also known as myosatellite cells), a population of mesodermal progenitor cells, are a major cell of origin for muscle fiber reprogramming. They are located between the basal lamina and sarcolemma of adult muscle fibers. They proliferate and differentiate into myoblasts, which fuse together to form skeletal muscle fibers through a process known as myogenesis $[2,11,96,148]$. Thus, these cells maintain homeostasis of normal skeletal muscle and promote their regeneration under traumatic or injurious conditions $[2,96,147]$. Their activation results in either production of new myoblasts or self-renewal and refill of the satellite cell pool $[2,11]$.

Proper migration of myogenic progenitor cells to the developing limb bud and subsequent myogenesis require the activity of the paired domain homeobox 3 (Pax3) transcription factor while 
Pax7 is required for the maintenance of the adult satellite cell pool [96]. Researchers have identified a group of basic helix-loop-helix (bHLH) proteins known as myogenic regulatory transcription factors (MRFs), which comprises myogenic factor 5 (Myf5), myogenic differentiation 1 (MyoD), myogenin, and myogenic regulatory factor 4 (MRF4). The MRFs family regulates specification of muscle satellite cell lineage, irreversible arrest of cell cycle of muscle precursor cells, and the activity of sarcomeric and muscle specific genes that facilitate sarcomere assembly and Pax3/7-derived myogenic differentiation [148,149]. Apart from muscle-specific Pax7-expressing satellite cells, a fiber type-specific myogenic progenitor population has been recently discovered, Twist2-expressing myogenic progenitors. Twist2 stem cells induce the growth and regeneration of type $\mathrm{IIb} / \mathrm{x}$ fibers in rodents [11]. Exhaustion of stem cells occurs with aging, which manifests by reduction of their number and ability to differentiate and proliferate $[125,150]$.

The number, activity, and fate of satellite cells, especially in fibers expressing type II (fast) myosin heavy chain, dramatically drop with aging, mainly due to the blunting effect of persistently elevated proinflammatory mediators [2]. Exhaustion of satellite cell pool results from induction of mesenchymal-fibrogenic and adipogenic conversions of satellite cells via events that occur in the immune system such as activation of TGF- $\beta$ and depletion of macrophages, which phagocyte damaged tissue debris [151]. Sarcopenia is a result of loss of functional contractile myofibrillar units, which satellite cells fail to counteract [5].

In vivo reprogramming is a strategy employed in regenerative medicine for enhancing myogenesis and tissue regeneration by promoting the differentiation and proliferation of muscle satellite cells $[46,147]$. Unfortunately, experimental efforts to induce myogenesis from satellite cells and different stem cells derived from muscle, perivascular cells, embryos, and induced pluripotency, have been unfruitful. In addition, this sort of treatment is associated with technical, economic, and regulatory complexities $[5,147]$.

\subsection{Microbiome Alterations}

The terms microbiome (microbes themselves) and microbiota (microbial genes or collective coding capacity) are used interchangeably to describe the complex community of co-evolved commensal microbes in a given location [113]. Human microbial flora exceeds the number of human body cells by at least 10-fold, comprising around 100 trillion microorganisms $[93,116]$. Every part of the human GI tract harbors more than 1000 different resident bacterial species (various strains are enterotoxigenic) in addition to a wide array of eukaryotes, archaea, fungi, protozoa, and viruses [152]. It is reported that gut microbiome matures by the age of three years and remains relatively stable over lifetime $[46,153]$. The symbiotic interactions of gut microbiome are essential for proper physiological functioning and good health. Therefore, gut microbiota represents a major environmental factor involved in dietary energy sparing and regulation of host immunity, endocrine response, and metabolism $[51,62,93,113]$. However, gut microbiome undergoes alterations, especially in advanced age due to skeletal muscle disuse/inactivity, poor dentition, chewing and taste problems, altered food intake, and poor food choices (e.g., low fiber diet) [113,152-154]. Alterations of microbiota involve propagation of enterotoxigenic bacterial strains such as Gram-negative bacilli Escherichia (E.) coli and reduction of beneficial bacteria such as Lactobacillus (L.) johnsonii $[155,156]$.

A plethora of evidence links gut microbiome with physiological decline of musculoskeletal function as well as major conditions that contribute to sarcopenia such as inflammation, physical inactivity, and nutritional deficiencies $[46,60,61,71,154,157,158]$. In details, dietary elements such as a diet rich in red meat or fat and deficient in fruits and vegetables can alter gut microbial composition and secretory patterns of gut peptides resulting in local mucosal inflammation [62,113]. The term "dysbiosis/intestinal permeability" describes disruptions in gut microbiome and epithelial barrier, that allow the passage of saturated fatty acids and toxins produced by Gram negative bacterial microflora such as lipopolysaccharide (LPS) into the systemic circulation [62,93]. As a natural ligand for specialized innate immune TLR 4, LPS activates cytokine production and a related com- 
plex network of signals interconnecting several organs [61,62]. Compared with younger groups, older adults exhibit higher levels of circulating LPS and indoxyl sulfate. The latter is a metabolite of bacteria that degrade tryptophan. Both LPS and indoxyl sulfate promote muscle atrophy by stimulating an inflammatory response that involves increased TLR4 expression in skeletal muscle [61]. Altogether, these reports suggest presence of a gut-muscle axis where age-related changes in gut microbiota may remotely influence the pathophysiology underlying skeletal muscle loss in old age [46,159].

Evolving knowledge emphasizes the causal nature of the relation between gut microbiota and muscle wasting [158]. Germ-free (GF) mice, which are devoid of microbes and live in sterile conditions, retain adequate muscle mass, and resist diet-induced obesity via mechanisms that involve activation of AMPK and PGC-1 $\alpha$ [93]. Experimentally, transferring gut microbiota from Rongchang pigs-obese pigs that express distinct gut microbiome structure as well as fiber characteristics and lipid metabolic profiles in their muscle- to GF mice resulted in a gut microbiota composition similar to donor pigs. Same as Rongchang pigs, recipient GF mice demonstrated increased proportion of slow-contracting fiber, reductions in fiber size and the percentage of fast IIb fibers, and increased fat mass and lipogenesis in the gastrocnemius muscle [158]. On the other hand, supplementing cachexic mice with oral probiotics containing L. reuteri, L. gasseri, and L. plantarum significantly restored intestinal microbial homeostasis, corrected gut dysbiosis, alleviated inflammation, and reduced the expression of atrophy markers (Atrogin-1, MuRF1, LC3, Cathepsin L) in the gastrocnemius and tibialis muscles [160,161]. Of interest, these effects were strain-dependent since L. acidophilus exhibited no effect on markers of inflammation or atrophy in cachexic mice [161].

Consistent results were reported in humans. Two studies could successfully distinguish between community-dwelling elders and their institutionalized counterparts through fecal microbiome signatures. Unlike old people in long-term care, communitydwelling elders have more diverse microbiome, better immune and nutritional status, less co-morbidities, and less frailty $[153,157]$. In the same regard, Picca and colleagues simultaneously characterized age-related alterations in gut microbial taxa along with systemic inflammation, and metabolic characteristics in a sample of older adults. They created a model to define an integrated signature of the aging phenotype. Their model successfully classified $91.7 \%$ and $87.5 \%$ of participants with and without physical frailty (sarcopenia), respectively. Physically frail and sarcopenic old individuals exhibited significantly higher serum levels of aspartic acid, lower circulating levels of threonine and MIP- $1 \alpha$, elevated abundance of Oscillospira and Ruminococcus microbial taxa, and reduced abundance of Barnesiellaceae and Christensenellaceae compared with healthy elders [60].

\section{Health-Related Consequences of Sarcopenia}

The deterioration of skeletal muscle quality represents a basic cause of poor QoL, immobility, disability, fall, fracture, hospitalization, prolonged hospital stay, increased hospital readmission, morbidity, and mortality in older adults $[5,16,18,49]$. Needless to say, hospitalization, even for a short time, is associated with increased risk for nosocomial infection in sarcopenic patients and remarkable drops in muscle strength and functional capacity, irrespective of age or baseline level of functioning. The negative effects of hospitalization on muscle function are even greater in older groups $[7,109]$, especially when affected by COVID-19 as discussed in Section 5.3. [32,78]. Sarcopenia also decreases survival and increases mortality in older adults by 2.1 -fold greater than in counterparts with proper muscle strength [2]. The highest occurrences of sarcopenia-related mortality are noticed in diseased conditions, especially those of metabolic and inflammatory nature such as diabetes mellitus and cancer $[7,18,33,92,162]$. These adverse effects seem to be universal e.g., with no differences between various ethnicities [162].

From a cost-oriented point of view, sarcopenia is a challenging health problem that imposes a major economic burden on healthcare systems [7]. Its direct cost in the United States in 2000 was USD 18.5 billion accounting for $1.5 \%$ of the total health care expendi- 
ture $[5,10]$. In the same respect, a recent study announced that the total annual health care cost of a person with sarcopenia in the United Kingdom is on average GBP 4592, which is almost 2.5 times greater than the cost of care of a person without sarcopenia $(£ 1885)$. Hence, sarcopenia increases the total annual cost of healthcare by GBP 2.5 billion [10]. Moreover, 11 out of 14 studies report significantly higher healthcare costs of treating sarcopenic patients compared with non-sarcopenic sarcopenic patients [163]. Therefore, decreasing the prevalence of sarcopenia by $10 \%$ is expected to decrease health care in the United States by USD 1.1 billion [1]. Consequently, effective management of sarcopenia will save billions of dollars due to reducing health care cost in addition to promoting functional independence and QoL [12].

\section{Current Pharmacological Management of Sarcopenia}

Being aware of the debilitating health outcomes associated with sarcopenia, several experiments have been conducted to investigate the muscle-promoting potential of various pharmacological agents such as testosterone, selective androgen receptor modulators, growth hormone replacement, myostatin inhibitors, anabolic steroids, and activin receptor antibodies [12,164]. Unfortunately, all these agents are highly experimental, serious adverse effects ensue, and available results fail to meet clinically relevant outcomes. Hence, until now, not a single drug has been approved $[12,15,59,164]$.

Given the current state of knowledge, the main prevention and treatment option for sarcopenia is a healthy lifestyle that comprises adequate nutritional intake (high protein and fiber diet) and physical activity $[5,15]$. However anabolic resistance common in old people limits the beneficial effects of diet and exercise on skeletal muscle [75]. Therefore, it is of importance to search for novel preventive and curative strategies for sarcopenia, which can take into account the multifactorial nature of skeletal muscle failure in old age [5,12].

Some herbal extracts are being tested as anti-sarcopenic agents such as sarconeos (BIO101), which contains an extract from the Maral root herb (Stemmacantha carthamoides) known as 20-hydroxyecdysone (20E) [165]. In parallel, researchers have tested the ability of numerous nutrients to prevent and remedy age-associated muscle loss [75]. As discussed above, vitamin D supplementation hinders muscle loss and decreases fat infiltration into muscle fibers [144,145]. Bee products such as royal jelly, propolis, and bee honey express strong anti-aging properties and enhance cellular functioning in various body tissues [70,117,166,167]. In fact, natural honey and propolis are reported to counteract muscle loss in cachectic animals [51,168,169]. The anti-cachectic properties of propolis and honey were most evident when combined with phenols extracted from grape seeds [168] and aloe vera (L.) Burm. f. (Xanthorrhoeaceae) [169].

We have also demonstrated that the use of royal jelly, propolis, and bee pollen before or during the early development of muscular dysfunction might prevent age-related muscular decline in experimental models [75]. Of importance, the muscle-promoting properties of vitamin D and bee products are maximized when combined with physical exercise $[75,145]$. Feeding obese mice milk naturally enriched with phenols from propolis improved gastrocnemius muscle mass compared with animals receiving unfortified milk [170]—indicating that bee products may facilitate the delivery of dietary nutrients to skeletal muscle to promote anabolism [75]. It is worth noting that vitamin D [21] and bee products [70,117] have immunomodulatory and neurotrophic effects (e.g., by increasing the production of nerve growth factor), which may prevent neuronal loss in patients with COVID-19. In addition, vitamin D [21,26] and bee products $[70,75]$ possess a capacity of correcting age-related pathologies that increase the risk for sarcopenia and COVID-19 such as hypertension, diabetes mellitus, and obesity. Thus, vitamin $\mathrm{D}$ and bee products are suggested as therapeutics that may protect against or facilitate the recovery from COVID-19 [21,23,26,75,171].

Intermittent fasting is another dietary intervention that involves remarkable regulation of signaling involved in metabolism, autophagy, antioxidant capacity, and immune regulation [125]. Intermittent fasting improves insulin sensitivity and corrects glucose metabolism [56] i.e., it reverts metabolic dysfunction, which is a key contributor to mus- 
cle catabolism and anabolic resistance [75]. Moreover, intermittent fasting is reported to significantly decrease obesity in individuals above the age of 16 [172], in a pregnant woman with gestational diabetes [56], as well as in post-menopausal women [173]. The effects of intermittent fasting in menopausal women show no reduction in muscle mass during fasting [173]. Although muscle performance was not evaluated in that study, we might expect that fasting may contribute to better muscle function given that it reduces fat infiltration into muscle fibers. However, empirical evidence is necessary in order to prove this hypothesis. Moreover, evidence shows that dietary restriction and ketogenic diet protect against influenza through a mechanism that entails improvement of mitochondrial metabolic activity, which is evidently altered in COVID-19 [174]. Therefore, it may be necessary to test the immunomodulatory effects of intermittent fasting on the risk for COVID-19 in susceptible people such as those with obesity and type 2 diabetes.

\section{Conclusions}

Sarcopenia is a multidimensional pathology that contributes to disability and high mortality in old people. Pathophysiological alterations involved in sarcopenia such as metabolic dysfunction, oxidative, stress, inflammation, and malnutrition promote immune dysfunction, thereby increasing the vulnerability to COVID-19 and its detrimental effects. Numerous studies report a poor prognosis and high fatality in COVID-19 patients with sarcopenia (physical frailty). In the meantime, the use of prevention and treatment options for sarcopenia may lower the risk for COVID-19 in old seniors, who represent a vast majority of the population struck by COVID-19 and its fatality.

Author Contributions: Both authors conceptualized the topic, wrote, and revised the manuscript. Both authors have read and agreed to the published version of the manuscript.

Funding: This study was supported by the Strategic Research Program for Brain Sciences from Japan Agency for Medical Research and development, AMED, Japan (Grant No. 18dm0107100h0003).

Institutional Review Board Statement: Not applicable.

Informed Consent Statement: Not applicable.

Data Availability Statement: Not applicable.

Conflicts of Interest: The authors declare no conflict of interest.

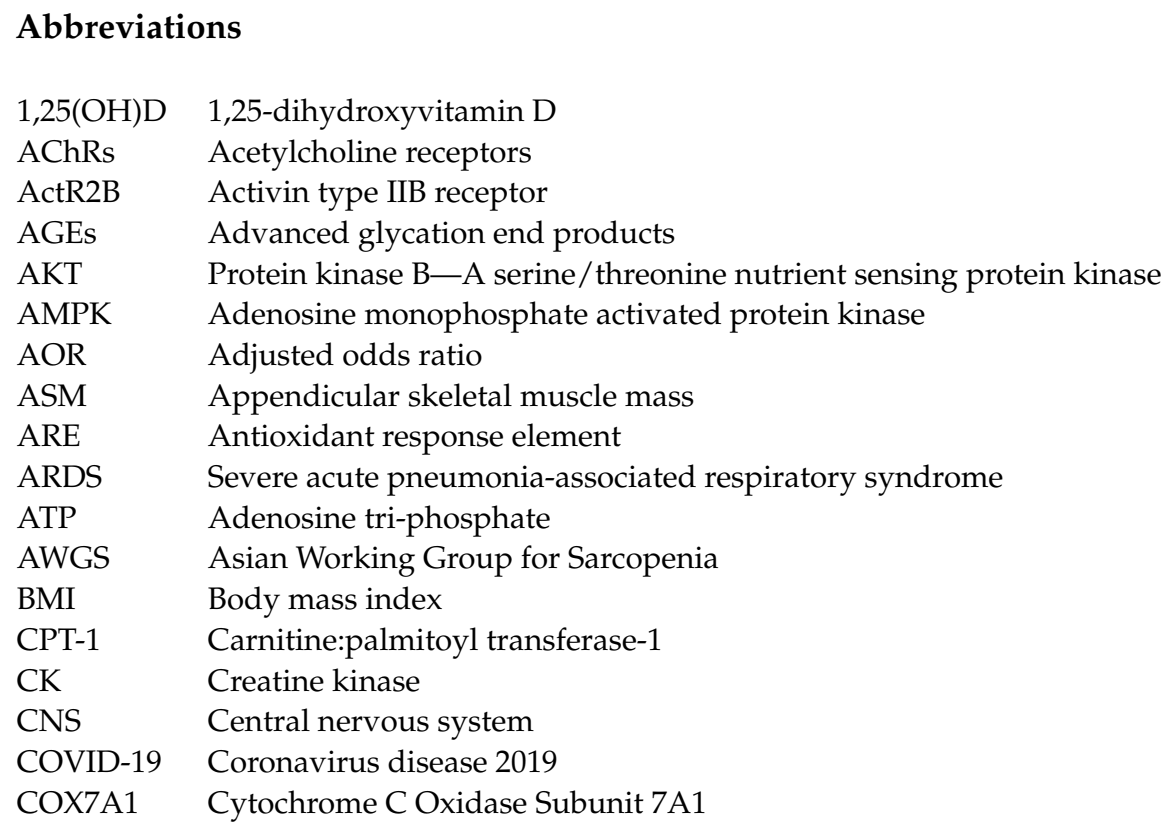




\begin{tabular}{|c|c|}
\hline CRP & C-reactive protein \\
\hline CREB & cAMP response element binding protein \\
\hline DAPK3 & Death-associated protein kinase 3 \\
\hline ERK & Extracellular signal-regulated kinase \\
\hline ER & Endoplasmic reticulum \\
\hline EUGMS & European Geriatric Medical Society \\
\hline EWGSOP & European Working Group on Sarcopenia in Older People \\
\hline FOXO & Forkhead box $\mathrm{O}$ \\
\hline GI & Gastrointestinal \\
\hline GLUT4 & Glucose transporter 4 \\
\hline GDF-8 & Growth differentiation factor- 8 \\
\hline GPRs & G-protein-coupled receptors \\
\hline HLH & Helix-loop-helix \\
\hline HR & Hazard ratio \\
\hline IGFs & Insulin-like growth factors \\
\hline ICFSR & International Conference on Frailty and Sarcopenia Research \\
\hline IL & Interleukin \\
\hline IWGS & International Working Group on Sarcopenia \\
\hline LBM & Lean body mass \\
\hline MAPK & Mitogen-activated protein kinase \\
\hline MIP-1 $\alpha$ & Macrophage inflammatory protein $1-\alpha$ \\
\hline mTOR & Mammalian target of rapamycin \\
\hline MCP-1 & Monocyte chemotactic protein 1 \\
\hline MRFs & Myogenic regulatory transcription factors \\
\hline $\mathrm{MPO}$ & Myeloperoxidase \\
\hline MRF4 & Myogenic regulatory factor 4 \\
\hline Myf5 & Myogenic factor 5 \\
\hline MyoD & Myogenic differentiation 1 \\
\hline NAD+ & Pyridine nucleotide nicotinamide adenine dinucleotide \\
\hline NADPH & Nicotinamide adenine dinucleotide phosphate hydrogen \\
\hline NF-kB & Nuclear factor kappa-B \\
\hline NRF2 & Nuclear factor erythroid 2/Nuclear respiratory factor 2 \\
\hline Pax3 & Paired domain homeobox 3 \\
\hline PDGF & Platelet-derived growth factor \\
\hline PGC- $1 \alpha$ & Peroxisome proliferator-activated receptor gamma coactivator 1 alpha \\
\hline QoL & Quality of life \\
\hline RAGE & Receptor for Advanced Glycation End products \\
\hline ROS & Reactive oxygen species \\
\hline SARS-CoV-2 & Severe acute respiratory syndrome-coronavirus- 2 \\
\hline STAT3 & Signal transducer and activator of transcription 3 \\
\hline SDs & Standard deviations \\
\hline SMI & Skeletal muscle mass index \\
\hline TGF- $\beta$ & Transforming growth factor- $\beta$ \\
\hline TNF & Tumor necrosis factor \\
\hline NDUFB6 & Ubiquinone Oxidoreductase Subunit B6 \\
\hline UPS & Ubiquitin-proteasome system \\
\hline
\end{tabular}

\section{References}

1. Vandewoude, M.F.; Alish, C.J.; Sauer, A.C.; Hegazi, R.A. Malnutrition-sarcopenia syndrome: Is this the future of nutrition screening and assessment for older adults? J. Aging Res. 2012, 2012, 651570. [CrossRef]

2. Wang, J.; Song, Y.; Gao, M.; Bai, X.; Chen, Z. Neuroprotective Effect of Several Phytochemicals and Its Potential Application in the Prevention of Neurodegenerative Diseases. Geriatrics 2016, 1, 29. [CrossRef] [PubMed]

3. Miljkovic, N.; Lim, J.Y.; Miljkovic, I.; Frontera, W.R. Aging of skeletal muscle fibers. Ann. Rehabil. Med. 2015, 39, 155-162. [CrossRef] [PubMed]

4. Venturelli, M.; Reggiani, C.; Richardson, R.S.; Schena, F. Skeletal Muscle Function in the Oldest-Old: The Role of Intrinsic and Extrinsic Factors. Exerc. Sport Sci. Rev. 2018, 46, 188-194. [CrossRef]

5. Okumura, N.; Toda, T.; Ozawa, Y.; Watanabe, K.; Ikuta, T.; Tatefuji, T.; Hashimoto, K.; Shimizu, T. Royal Jelly Delays Motor Functional Impairment During Aging in Genetically Heterogeneous Male Mice. Nutrients 2018, 10, 1191. [CrossRef] 
6. Liguori, I.; Russo, G.; Aran, L.; Bulli, G.; Curcio, F.; Della-Morte, D.; Gargiulo, G.; Testa, G.; Cacciatore, F.; Bonaduce, D.; et al. Sarcopenia: Assessment of disease burden and strategies to improve outcomes. Clin. Interv. Aging 2018, 13, 913-927. [CrossRef]

7. Perkisas, S.; Vandewoude, M. Where frailty meets diabetes. Diabetes Metab. Res. 2016, 32, 261-267. [CrossRef]

8. Drey, M.; Hasmann, S.E.; Krenovsky, J.P.; Hobert, M.A.; Straub, S.; Elshehabi, M.; von Thaler, A.K.; Fallgatter, A.J.; Eschweiler, G.W.; Suenkel, U.; et al. Associations between Early Markers of Parkinson's Disease and Sarcopenia. Front. Aging Neurosci. $2017,9,53$. [CrossRef]

9. Niu, K.; Guo, H.; Guo, Y.; Ebihara, S.; Asada, M.; Ohrui, T.; Furukawa, K.; Ichinose, M.; Yanai, K.; Kudo, Y.; et al. Royal jelly prevents the progression of sarcopenia in aged mice in vivo and in vitro. J. Gerontol. Ser. A Biol. Sci. Med. Sci. 2013, 68, 1482-1492. [CrossRef]

10. Pinedo-Villanueva, R.; Westbury, L.D.; Syddall, H.E.; Sanchez-Santos, M.T.; Dennison, E.M.; Robinson, S.M.; Cooper, C. Health Care Costs Associated With Muscle Weakness: A UK Population-Based Estimate. Calcif. Tissue Int. 2019, 104, 137-144. [CrossRef]

11. Rong, S.; Wang, L.; Peng, Z.; Liao, Y.; Li, D.; Yang, X.; Nuessler, A.K.; Liu, L.; Bao, W.; Yang, W. The mechanisms and treatments for sarcopenia: Could exosomes be a perspective research strategy in the future? J. Cachexia Sarcopenia Muscle 2020, 11, 348-365. [CrossRef]

12. Hardee, J.P.; Lynch, G.S. Current pharmacotherapies for sarcopenia. Expert Opin. Pharmacother. 2019, 20, 1645-1657. [CrossRef]

13. Mori, H.; Kuroda, A.; Ishizu, M.; Ohishi, M.; Takashi, Y.; Otsuka, Y.; Taniguchi, S.; Tamaki, M.; Kurahashi, K.; Yoshida, S.; et al. Association of accumulated advanced glycation end-products with a high prevalence of sarcopenia and dynapenia in patients with type 2 diabetes. J. Diabetes Investig. 2019, 10, 1332-1340. [CrossRef] [PubMed]

14. Sakuma, K.; Aoi, W.; Yamaguchi, A. Molecular mechanism of sarcopenia and cachexia: Recent research advances. Pflug. Arch. Eur. J. Phys. 2017, 469, 573-591. [CrossRef]

15. Keller, K. Sarcopenia. Wien. Med. Wochenschr. 2019, 169, 157-172. [CrossRef] [PubMed]

16. Volpato, S.; Bianchi, L.; Cherubini, A.; Landi, F.; Maggio, M.; Savino, E.; Bandinelli, S.; Ceda, G.P.; Guralnik, J.M.; Zuliani, G.; et al. Prevalence and clinical correlates of sarcopenia in community-dwelling older people: Application of the EWGSOP definition and diagnostic algorithm. J. Gerontol. Ser. A Biol. Sci. Med. Sci. 2014, 69, 438-446. [CrossRef]

17. Vatic, M.; von Haehling, S.; Ebner, N. Inflammatory biomarkers of frailty. Exp. Gerontol. 2020, 133, 110858. [CrossRef]

18. Gensous, N.; Bacalini, M.G.; Franceschi, C.; Meskers, C.G.M.; Maier, A.B.; Garagnani, P. Age-Related DNA Methylation Changes: Potential Impact on Skeletal Muscle Aging in Humans. Front. Physiol. 2019, 10, 996. [CrossRef]

19. Goyal, B.; Goyal, D. Targeting the Dimerization of the Main Protease of Coronaviruses: A Potential Broad-Spectrum Therapeutic Strategy. ACS Comb. Sci. 2020, 22, 297-305. [CrossRef]

20. Ali, A.M.; Kunugi, H. Propolis, bee honey, and their components protect against coronavirus disease 2019 (Covid-19): A review of in silico, in vitro, and clinical studies. Molecular 2021, 26, 1232. [CrossRef] [PubMed]

21. Xu, Y.; Baylink, D.J.; Chen, C.S.; Reeves, M.E.; Xiao, J.; Lacy, C.; Lau, E.; Cao, H. The importance of vitamin d metabolism as a potential prophylactic, immunoregulatory and neuroprotective treatment for COVID-19. J. Transl. Med. 2020, 18, 322. [CrossRef]

22. Zhou, Y.; Fu, B.; Zheng, X.; Wang, D.; Zhao, C.; Qi, Y.; Sun, R.; Tian, Z.; Xu, X.; Wei, H. Pathogenic T-cells and inflammatory monocytes incite inflammatory storms in severe COVID-19 patients. Natl. Sci. Rev. 2020, 7, 998-1002. [CrossRef]

23. Ali, A.M.; Kunugi, H. Approaches to nutritional screening in patients with Coronavirus Disease 2019 (COVID-19). Int. J. Environ. Res. Public Health 2021, 18, 2772. [CrossRef]

24. Ali, A.M.; Kunugi, H. Hypoproteinemia predicts disease severity and mortality in COVID-19: A call for action. Diagn. Pathol. 2021, 16, s13000-s13021. [CrossRef]

25. Zabetakis, I.; Lordan, R.; Norton, C.; Tsoupras, A. COVID-19: The Inflammation Link and the Role of Nutrition in Potential Mitigation. Nutrients 2020, 12, 1466. [CrossRef]

26. Carter, S.J.; Baranauskas, M.N.; Fly, A.D. Considerations for Obesity, Vitamin D, and Physical Activity Amid the COVID-19 Pandemic. Obesity 2020, 28, 1176-1177. [CrossRef] [PubMed]

27. Laviano, A.; Koverech, A.; Zanetti, M. Nutrition support in the time of SARS-CoV-2 (COVID-19). Nutrition 2020, 74, 110834. [CrossRef] [PubMed]

28. Labenz, C.; Kremer, W.M.; Schattenberg, J.M.; Wörns, M.A.; Toenges, G.; Weinmann, A.; Galle, P.R.; Sprinzl, M.F. Clinical Frailty Scale for risk stratification in patients with SARS-CoV-2 infection. J. Investig. Med. Off. Publ. Am. Fed. Clin. Res. 2020, 68, 1199-1202. [CrossRef]

29. Al Rihani, S.B.; Smith, M.K.; Bikmetov, R.; Deodhar, M.; Dow, P.; Turgeon, J.; Michaud, V. Risk of Adverse Drug Events Following the Virtual Addition of COVID-19 Repurposed Drugs to Drug Regimens of Frail Older Adults with Polypharmacy. J. Clin. Med. 2020, 9, 2591. [CrossRef] [PubMed]

30. De Smet, R.; Mellaerts, B.; Vandewinckele, H.; Lybeert, P.; Frans, E.; Ombelet, S.; Lemahieu, W.; Symons, R.; Ho, E.; Frans, J.; et al. Frailty and Mortality in Hospitalized Older Adults With COVID-19: Retrospective Observational Study. J. Am. Med. Dir. Assoc. 2020, 21, 928-932.e1. [CrossRef]

31. Bellelli, G.; Rebora, P.; Valsecchi, M.G.; Bonfanti, P.; Citerio, G. Frailty index predicts poor outcome in COVID-19 patients. Intensive Care Med. 2020, 46, 1634-1636. [CrossRef] [PubMed]

32. Hewitt, J.; Carter, B.; Vilches-Moraga, A.; Quinn, T.J.; Braude, P.; Verduri, A.; Pearce, L.; Stechman, M.; Short, R.; Price, A.; et al The effect of frailty on survival in patients with COVID-19 (COPE): A multicentre, European, observational cohort study. Lancet Public Health 2020, 5, e444-e451. [CrossRef] 
33. Riuzzi, F.; Sorci, G.; Sagheddu, R.; Chiappalupi, S.; Salvadori, L.; Donato, R. RAGE in the pathophysiology of skeletal muscle. J. Cachexia Sarcopenia Muscle 2018, 9, 1213-1234. [CrossRef]

34. Egawa, T.; Ohno, Y.; Yokoyama, S.; Yokokawa, T.; Tsuda, S.; Goto, K.; Hayashi, T. The Protective Effect of Brazilian Propolis against Glycation Stress in Mouse Skeletal Muscle. Foods 2019, 8, 439. [CrossRef] [PubMed]

35. Suetta, C.; Maier, A.B. Is muscle failure a better term than sarcopenia? J. Cachexia Sarcopenia Muscle 2019, 10, 1146-1147. [CrossRef]

36. Ali, A.M.; Kunugi, H. Screening for sarcopenia (physical frailty) in the COVID-19 era. Int. J. Endocrinol. 2021, 2021, 5563960. [CrossRef] [PubMed]

37. Welch, A.A.; Hayhoe, R.P.G.; Cameron, D. The relationships between sarcopenic skeletal muscle loss during ageing and macronutrient metabolism, obesity and onset of diabetes. Proc. Nutr. Soc. 2020, 79, 158-169. [CrossRef]

38. Argiles, J.M.; Campos, N.; Lopez-Pedrosa, J.M.; Rueda, R.; Rodriguez-Manas, L. Skeletal Muscle Regulates Metabolism via Interorgan Crosstalk: Roles in Health and Disease. J. Am. Med. Dir. Assoc. 2016, 17, 789-796. [CrossRef]

39. Wilkinson, D.J.; Piasecki, M.; Atherton, P.J. The age-related loss of skeletal muscle mass and function: Measurement and physiology of muscle fibre atrophy and muscle fibre loss in humans. Ageing Res. Rev. 2018, 47, 123-132. [CrossRef]

40. Rosenberg, I.H. Sarcopenia: Origins and clinical relevance. J. Nutr. 1997, 127, 990s-991s. [CrossRef]

41. Cruz-Jentoft, A.J.; Kiesswetter, E.; Drey, M.; Sieber, C.C. Nutrition, frailty, and sarcopenia. Aging Clin. Exp. Res. 2017, 29, 43-48. [CrossRef] [PubMed]

42. Phung, L.A.; Karvinen, S.M.; Colson, B.A.; Thomas, D.D.; Lowe, D.A. Age affects myosin relaxation states in skeletal muscle fibers of female but not male mice. PLoS ONE 2018, 13, e0199062. [CrossRef]

43. Janssen, I.; Heymsfield, S.B.; Ross, R. Low relative skeletal muscle mass (sarcopenia) in older persons is associated with functional impairment and physical disability. J. Am. Geriatr. Soc. 2002, 50, 889-896. [CrossRef]

44. Chen, L.K.; Liu, L.K.; Woo, J.; Assantachai, P.; Auyeung, T.W.; Bahyah, K.S.; Chou, M.Y.; Chen, L.Y.; Hsu, P.S.; Krairit, O.; et al. Sarcopenia in Asia: Consensus report of the Asian Working Group for Sarcopenia. J. Am. Med. Dir. Assoc. 2014, $15,95-101$. [CrossRef]

45. Cruz-Jentoft, A.J.; Baeyens, J.P.; Bauer, J.M.; Boirie, Y.; Cederholm, T.; Landi, F.; Martin, F.C.; Michel, J.P.; Rolland, Y.; Schneider, S.M.; et al. Sarcopenia: European consensus on definition and diagnosis: Report of the European Working Group on Sarcopenia in Older People. Age Ageing 2010, 39, 412-423. [CrossRef]

46. Ticinesi, A.; Lauretani, F.; Milani, C.; Nouvenne, A.; Tana, C.; Del Rio, D.; Maggio, M.; Ventura, M.; Meschi, T. Aging Gut Microbiota at the Cross-Road between Nutrition, Physical Frailty, and Sarcopenia: Is There a Gut-Muscle Axis? Nutrients 2017, 9 , 1303. [CrossRef] [PubMed]

47. Favaro-Moreira, N.C.; Krausch-Hofmann, S.; Matthys, C.; Vereecken, C.; Vanhauwaert, E.; Declercq, A.; Bekkering, G.E.; Duyck, J. Risk Factors for Malnutrition in Older Adults: A Systematic Review of the Literature Based on Longitudinal Data. Adv. Nutr. 2016, 7, 507-522. [CrossRef]

48. Jeejeebhoy, K.N. Malnutrition, fatigue, frailty, vulnerability, sarcopenia and cachexia: Overlap of clinical features. Curr. Opin. Clin. Nutr. Metab. Care 2012, 15, 213-219. [CrossRef]

49. Gingrich, A.; Volkert, D.; Kiesswetter, E.; Thomanek, M.; Bach, S.; Sieber, C.C.; Zopf, Y. Prevalence and overlap of sarcopenia, frailty, cachexia and malnutrition in older medical inpatients. BMC Geriatr. 2019, 19, 120. [CrossRef]

50. Zopf, Y.; Schink, K.; Reljic, D.; Herrmann, H.J.; Dieterich, W.; Kiesswetter, E.; Sieber, C.C.; Neurath, M.F.; Volkert, D. Assessing cachexia in older patients: Different definitions-But which one is the most practical for clinical routine? Arch. Gerontol. Geriatr. 2020, 86, 103943. [CrossRef]

51. Ali, A.M.; Ali, E.M.; Ahmed, M.S.; Hendawy, A.O. Targeting gut microbiome and the recovery of muscle loss associated with cancer (cachexia): An overview of the possible effect of bee products. Med. Leg. Update 2021, 21, 163-171. [CrossRef]

52. Tieland, M.; Trouwborst, I.; Clark, B.C. Skeletal muscle performance and ageing. J. Cachexia Sarcopenia Muscle 2018, 9, 3-19. [CrossRef] [PubMed]

53. Pedone, C.; Costanzo, L.; Cesari, M.; Bandinelli, S.; Ferrucci, L.; Antonelli Incalzi, R. Are Performance Measures Necessary to Predict Loss of Independence in Elderly People? J. Gerontol. Ser. A Biol. Sci. Med. Sci. 2016, 71, 84-89. [CrossRef]

54. Rockwood, K.; Mitnitski, A. Frailty in relation to the accumulation of deficits. J. Gerontol. Ser. A Biol. Sci. Med. Sci. 2007, 62, 722-727. [CrossRef]

55. Fried, L.P.; Tangen, C.M.; Walston, J.; Newman, A.B.; Hirsch, C.; Gottdiener, J.; Seeman, T.; Tracy, R.; Kop, W.J.; Burke, G.; et al. Frailty in older adults: Evidence for a phenotype. J. Gerontol. Ser. A Biol. Sci. Med. Sci. 2001, 56, M146-M156. [CrossRef]

56. Ali, A.M.; Kunugi, H. Intermittent fasting, dietary modifications, and exercise for the control of gestational diabetes and maternal mood dysregulation: A review and a case report. Int. J. Environ. Res. Public Health 2020, 17, 9379. [CrossRef]

57. Ali, A.M.; Ahmed, A.H.; Smail, L. Psychological Climacteric Symptoms and Attitudes toward Menopause among Emirati Women. Int. J. Environ. Res. Public Health 2020, 17, 5028. [CrossRef]

58. Breucker, S.D.; Luce, S.; Njemini, R.; Bautmans, I.; Decoster, L.; Mets, T.; Pepersack, T. Analysis of inflammatory markers and hormones in old cancer patients: A descriptive study. Exp. Gerontol. 2020, 130, 110787. [CrossRef]

59. Consitt, L.A.; Clark, B.C. The Vicious Cycle of Myostatin Signaling in Sarcopenic Obesity: Myostatin Role in Skeletal Muscle Growth, Insulin Signaling and Implications for Clinical Trials. J. Frailty Aging 2018, 7, 21-27. [CrossRef] [PubMed] 
60. Picca, A.; Ponziani, F.R.; Calvani, R.; Marini, F.; Biancolillo, A.; Coelho-Junior, H.J.; Gervasoni, J.; Primiano, A.; Putignani, L.; Del Chierico, F.; et al. Gut Microbial, Inflammatory and Metabolic Signatures in Older People with Physical Frailty and Sarcopenia: Results from the BIOSPHERE Study. Nutrients 2019, 12, 65. [CrossRef] [PubMed]

61. Grosicki, G.J.; Fielding, R.A.; Lustgarten, M.S. Gut Microbiota Contribute to Age-Related Changes in Skeletal Muscle Size, Composition, and Function: Biological Basis for a Gut-Muscle Axis. Calcif. Tissue Int. 2018, 102, 433-442. [CrossRef] [PubMed]

62. Bleau, C.; Karelis, A.D.; St-Pierre, D.H.; Lamontagne, L. Crosstalk between intestinal microbiota, adipose tissue and skeletal muscle as an early event in systemic low-grade inflammation and the development of obesity and diabetes. Diabetes Metab. Res. Rev. 2015, 31, 545-561. [CrossRef] [PubMed]

63. Yoo, J.H.; Park, S.W.; Jun, J.E.; Jin, S.-M.; Hur, K.Y.; Lee, M.-K.; Kang, M.; Kim, G.; Kim, J.H. Relationship between low skeletal muscle mass, sarcopenic obesity and left ventricular diastolic dysfunction in Korean adults. Diabetes/Metab. Res. Rev. 2021, 37, e3363. [CrossRef]

64. Cipolloni, L.; Sessa, F.; Bertozzi, G.; Baldari, B.; Cantatore, S.; Testi, R.; D’Errico, S.; Di Mizio, G.; Asmundo, A.; Castorina, S.; et al. Preliminary Post-Mortem COVID-19 Evidence of Endothelial Injury and Factor VIII Hyperexpression. Diagnostics 2020, 10, 575. [CrossRef]

65. Sawaya, Y.; Ishizaka, M.; Kubo, A.; Shiba, T.; Hirose, T.; Onoda, K.; Maruyama, H.; Urano, T. Association between skeletal muscle mass index and lung function/respiratory muscle strength in older adults requiring long-term care or support. J. Phys. Ther. Sci. 2020, 32, 754-759. [CrossRef]

66. Ali, A.M.; Kunugi, H. Skeletal muscle damage in COVID-19: A call for action. Medicina 2021, 57, 372. [CrossRef]

67. Yoo, J.H.; Kim, G.; Park, S.W.; Choi, M.S.; Ahn, J.; Jin, S.M.; Hur, K.Y.; Lee, M.K.; Kang, M.; Kim, J.H. Effects of low skeletal muscle mass and sarcopenic obesity on albuminuria: A 7-year longitudinal study. Sci. Rep. 2020, 10, 5774. [CrossRef] [PubMed]

68. Neumann-Podczaska, A.; Al-Saad, S.R.; Karbowski, L.M.; Chojnicki, M.; Tobis, S.; Wieczorowska-Tobis, K. COVID 19-Clinical Picture in the Elderly Population: A Qualitative Systematic Review. Aging Dis. 2020, 11, 988-1008. [CrossRef] [PubMed]

69. Tehrani, S.; Killander, A.; Åstrand, P.; Jakobsson, J.; Gille-Johnson, P. Risk factors for death in adult COVID-19 patients: Frailty predicts fatal outcome in older patients. Int. J. Infect. Dis. 2021, 102, 415-421. [CrossRef]

70. Ali, A.M.; Kunugi, H. Royal jelly as an intelligent anti-aging-a focus on cognitive aging and Alzheimer's disease: A review. Antioxidants 2020, 9, 937. [CrossRef] [PubMed]

71. Ali, A.M.; Kunugi, H. Corona Virus Disease 2019 (COVID-19): A pandemic that threatens physical and mental health by promoting physical inactivity. Sports Med. Health Sci. 2020, 2, 221-223. [CrossRef]

72. Zhao, X.; Li, Y.; Ge, Y.; Shi, Y.; Lv, P.; Zhang, J.; Fu, G.; Zhou, Y.; Jiang, K.; Lin, N.; et al. Evaluation of Nutrition Risk and Its Association With Mortality Risk in Severely and Critically Ill COVID-19 Patients. J. Parenter. Enter. Nutr. 2020, 45, 32-42. [CrossRef]

73. Jiménez-Pavón, D.; Carbonell-Baeza, A.; Lavie, C.J. Physical exercise as therapy to fight against the mental and physical consequences of COVID-19 quarantine: Special focus in older people. Prog. Cardiovasc. Dis. 2020, 63, 386-388. [CrossRef] [PubMed]

74. Moro, T.; Paoli, A. When COVID-19 affects muscle: Effects of quarantine in older adults. Eur. J. Transl. Myol. 2020, 30, 9069. [CrossRef] [PubMed]

75. Ali, A.M.; Kunugi, H. Apitherapy for age-related skeletal muscle dysfunction (sarcopenia): A review on the effects of royal jelly, propolis, and bee pollen. Foods 2020, 9, 1362. [CrossRef]

76. Bhasker, A.G.; Greve, J.W. Are Patients Suffering from Severe Obesity Getting a Raw Deal During COVID-19 Pandemic? Obes. Surg. 2020, 30, 4107-4108. [CrossRef]

77. Azzolino, D.; Saporiti, E.; Proietti, M.; Cesari, M. Nutritional Considerations in Frail Older Patients with COVID-19. J. Nutr. Health Aging 2020, 24, 696-698. [CrossRef]

78. Ma, Y.; Hou, L.; Yang, X.; Huang, Z.; Yang, X.; Zhao, N.; He, M.; Shi, Y.; Kang, Y.; Yue, J.; et al. The association between frailty and severe disease among COVID-19 patients aged over 60 years in China: A prospective cohort study. BMC Med. 2020, 18, 274. [CrossRef] [PubMed]

79. Aw, D.; Woodrow, L.; Ogliari, G.; Harwood, R. Association of Frailty with Mortality in Older Inpatients with Covid-19: A Cohort Study. Age Ageing 2020, 49, 915-922. [CrossRef]

80. Sriram, S.; Subramanian, S.; Sathiakumar, D.; Venkatesh, R.; Salerno, M.S.; McFarlane, C.D.; Kambadur, R.; Sharma, M. Modulation of reactive oxygen species in skeletal muscle by myostatin is mediated through NF-kappaB. Aging Cell 2011, 10, 931-948. [CrossRef]

81. Ali, A.M.; Kunugi, H. The effects of royal jelly acid, 10-hydroxy-trans-2-decenoic acid, on neuroinflammation and oxidative stress in astrocytes stimulated with lipopolysaccharide and hydrogen peroxide. Immuno 2021, 1, 212-222. [CrossRef]

82. Miko, A.; Poto, L.; Matrai, P.; Hegyi, P.; Furedi, N.; Garami, A.; Illes, A.; Solymar, M.; Vincze, A.; Balasko, M.; et al. Gender difference in the effects of interleukin-6 on grip strength; a systematic review and meta-analysis. BMC Geriatr. 2018, 18, 107. [CrossRef]

83. Marzetti, E.; Picca, A.; Marini, F.; Biancolillo, A.; Coelho-Junior, H.J.; Gervasoni, J.; Bossola, M.; Cesari, M.; Onder, G.; Landi, F.; et al. Inflammatory signatures in older persons with physical frailty and sarcopenia: The frailty "cytokinome" at its core. Exp. Gerontol. 2019, 122, 129-138. [CrossRef] 
84. Miyatake, S.; Shimizu-Motohashi, Y.; Takeda, S.; Aoki, Y. Anti-inflammatory drugs for Duchenne muscular dystrophy: Focus on skeletal muscle-releasing factors. Drug Des. Dev. Ther. 2016, 10, 2745-2758. [CrossRef]

85. Saleh, J.; Peyssonnaux, C.; Singh, K.K.; Edeas, M. Mitochondria and microbiota dysfunction in COVID-19 pathogenesis. Mitochondrion 2020, 54, 1-7. [CrossRef]

86. Anagnostou, M.E.; Hepple, R.T. Mitochondrial Mechanisms of Neuromuscular Junction Degeneration with Aging. Cells 2020, 9 , 197. [CrossRef]

87. Genin, E.C.; Madji Hounoum, B.; Bannwarth, S.; Fragaki, K.; Lacas-Gervais, S.; Mauri-Crouzet, A.; Lespinasse, F.; Neveu, J.; Ropert, B.; Auge, G.; et al. Mitochondrial defect in muscle precedes neuromuscular junction degeneration and motor neuron death in CHCHD10(S59L/+) mouse. Acta Neuropathol. 2019, 138, 123-145. [CrossRef] [PubMed]

88. Menzies, K.; Zaldivar-Jolissaint, J.F.; Auwerx, J. Sirtuins as Metabolic Modulators of Muscle Plasticity. In Sirtuins, Proteins and Cell Regulation; Houtkooper, R., Ed.; Springer: Dordrecht, The Netherlands, 2016; Volume 10.

89. Becker, C.; Lord, S.R.; Studenski, S.A.; Warden, S.J.; Fielding, R.A.; Recknor, C.P.; Hochberg, M.C.; Ferrari, S.L.; Blain, H.; Binder, E.F.; et al. Myostatin antibody (LY2495655) in older weak fallers: A proof-of-concept, randomised, phase 2 trial. Lancet Diabetes Endocrinol. 2015, 3, 948-957. [CrossRef]

90. Camporez, J.P.; Petersen, M.C.; Abudukadier, A.; Moreira, G.V.; Jurczak, M.J.; Friedman, G.; Haqq, C.M.; Petersen, K.F.; Shulman, G.I. Anti-myostatin antibody increases muscle mass and strength and improves insulin sensitivity in old mice. Proc. Natl. Acad. Sci. USA 2016, 113, 2212-2217. [CrossRef]

91. Zarbafian, M.; Dayan, S.; Fabi, S.G. Teachings from COVID-19 and aging-An oxidative process. J. Cosmet. Dermatol. 2020, 19, 3171-3176. [CrossRef] [PubMed]

92. Rhoads, T.W.; Clark, J.P.; Gustafson, G.E.; Miller, K.N.; Conklin, M.W.; DeMuth, T.M.; Berres, M.E.; Eliceiri, K.W.; Vaughan, L.K.; Lary, C.W.; et al. Molecular and Functional Networks Linked to Sarcopenia Prevention by Caloric Restriction in Rhesus Monkeys. Cell Syst. 2020, 10, 156-168. [CrossRef]

93. Bindels, L.B.; Delzenne, N.M. Muscle wasting: The gut microbiota as a new therapeutic target? Int. J. Biochem. Cell Biol. 2013, 45, 2186-2190. [CrossRef]

94. Kim, Y.; Triolo, M.; Hood, D.A. Impact of Aging and Exercise on Mitochondrial Quality Control in Skeletal Muscle. Oxid. Med. Cell. Longev. 2017, 2017, 3165396. [CrossRef]

95. Mudry, J.M.; Lassiter, D.G.; Nylen, C.; Garcia-Calzon, S.; Naslund, E.; Krook, A.; Zierath, J.R. Insulin and Glucose Alter Death-Associated Protein Kinase 3 (DAPK3) DNA Methylation in Human Skeletal Muscle. Diabetes 2017, 66, 651-662. [CrossRef] [PubMed]

96. Laker, R.C.; Ryall, J.G. DNA Methylation in Skeletal Muscle Stem Cell Specification, Proliferation, and Differentiation. Stem Cells Int. 2016, 2016, 5725927. [CrossRef] [PubMed]

97. Giresi, P.G.; Stevenson, E.J.; Theilhaber, J.; Koncarevic, A.; Parkington, J.; Fielding, R.A.; Kandarian, S.C. Identification of a molecular signature of sarcopenia. Physiol. Genom. 2005, 21, 253-263. [CrossRef]

98. Begue, G.; Raue, U.; Jemiolo, B.; Trappe, S. DNA methylation assessment from human slow- and fast-twitch skeletal muscle fibers. J. Appl. Phys. 2017, 122, 952-967. [CrossRef]

99. Davegardh, C.; Hall Wedin, E.; Broholm, C.; Henriksen, T.I.; Pedersen, M.; Pedersen, B.K.; Scheele, C.; Ling, C. Sex influences DNA methylation and gene expression in human skeletal muscle myoblasts and myotubes. Stem Cell Res. Ther. 2019, 10, 26. [CrossRef] [PubMed]

100. Waters, D.L.; Vlietstra, L.; Qualls, C.; Morley, J.E.; Vellas, B. Sex-specific muscle and metabolic biomarkers associated with gait speed and cognitive transitions in older adults: A 9-year follow-up. GeroScience 2020, 42, 585-593. [CrossRef]

101. Mueller, A.L.; McNamara, M.S.; Sinclair, D.A. Why does COVID-19 disproportionately affect older people? Aging 2020, 12, 9959-9981. [CrossRef]

102. Boisard, S.; Shahali, Y.; Aumond, M.-C.; Derbré, S.; Blanchard, P.; Dadar, M.; Le Ray, A.-M.; Richomme, P. Anti-AGE activity of poplar-type propolis: Mechanism of action of main phenolic compounds. Int. J. Food Sci. 2020, 55, 453-460. [CrossRef]

103. Egawa, T.; Ohno, Y.; Yokoyama, S.; Goto, A.; Ito, R.; Hayashi, T.; Goto, K. The effect of advanced glycation end products on cellular signaling molecules in skeletal muscle. J. Phys. Fit. Sports Med. 2018, 7, 229-238. [CrossRef]

104. He, T.; Qu, R.; Qin, C.; Wang, Z.; Zhang, Y.; Shao, X.; Lu, T. Potential mechanisms of Chinese Herbal Medicine that implicated in the treatment of COVID-19 related renal injury. Saudi Pharm. J. SPJ Off. Publ. Saudi Pharm. Soc. 2020, 28, 1138-1148. [CrossRef]

105. Pinto-Junior, D.C.; Silva, K.S.; Michalani, M.L.; Yonamine, C.Y.; Esteves, J.V.; Fabre, N.T.; Thieme, K.; Catanozi, S.; Okamoto, M.M.; Seraphim, P.M.; et al. Advanced glycation end products-induced insulin resistance involves repression of skeletal muscle GLUT4 expression. Sci. Rep. 2018, 8, 8109. [CrossRef] [PubMed]

106. Marzetti, E.; Calvani, R.; Tosato, M.; Cesari, M.; Di Bari, M.; Cherubini, A.; Broccatelli, M.; Savera, G.; D’Elia, M.; Pahor, M.; et al. Physical activity and exercise as countermeasures to physical frailty and sarcopenia. Aging Clin. Exp. Res. 2017, $29,35-42$. [CrossRef] [PubMed]

107. Szentesi, P.; Csernoch, L.; Dux, L.; Keller-Pinter, A. Changes in Redox Signaling in the Skeletal Muscle with Aging. Oxidative Med. Cell. Longev. 2019, 2019, 4617801. [CrossRef]

108. Bressa, C.; Bailen-Andrino, M.; Perez-Santiago, J.; Gonzalez-Soltero, R.; Perez, M.; Montalvo-Lominchar, M.G.; Mate-Munoz, J.L.; Dominguez, R.; Moreno, D.; Larrosa, M. Differences in gut microbiota profile between women with active lifestyle and sedentary women. PLoS ONE 2017, 12, e0171352. [CrossRef] [PubMed] 
109. Mahmassani, Z.S.; Reidy, P.T.; McKenzie, A.I.; Stubben, C.; Howard, M.T.; Drummond, M.J. Disuse-induced insulin resistance susceptibility coincides with a dysregulated skeletal muscle metabolic transcriptome. J. Appl. Phys. 2019, 126, 1419-1429. [CrossRef]

110. Latham, C.M.; Wagner, A.L.; Urschel, K.L. Effects of dietary amino acid supplementation on measures of whole-body and muscle protein metabolism in aged horses. J. Anim. Physiol. Anim. Nutr. 2019, 103, 283-294. [CrossRef]

111. Bocco, B.M.; Louzada, R.A.; Silvestre, D.H.; Santos, M.C.; Anne-Palmer, E.; Rangel, I.F.; Abdalla, S.; Ferreira, A.C.; Ribeiro, M.O.; Gereben, B.; et al. Thyroid hormone activation by type 2 deiodinase mediates exercise-induced peroxisome proliferator-activated receptor-gamma coactivator-1alpha expression in skeletal muscle. J. Physiol. 2016, 594, 5255-5269. [CrossRef]

112. Sanchez-Sanchez, J.L.; Manas, A.; Garcia-Garcia, F.J.; Ara, I.; Carnicero, J.A.; Walter, S.; Rodriguez-Manas, L. Sedentary behaviour, physical activity, and sarcopenia among older adults in the TSHA: Isotemporal substitution model. J. Cachexia Sarcopenia Muscle 2019, 10, 188-198. [CrossRef]

113. O'Toole, P.W.; Shiels, P.G. The role of the microbiota in sedentary lifestyle disorders and ageing: Lessons from the animal kingdom. J. Intern. Med. 2020, 287, 271-282. [CrossRef] [PubMed]

114. Barton, W.; Penney, N.C.; Cronin, O.; Garcia-Perez, I.; Molloy, M.G.; Holmes, E.; Shanahan, F.; Cotter, P.D.; O’Sullivan, O. The microbiome of professional athletes differs from that of more sedentary subjects in composition and particularly at the functional metabolic level. Gut 2018, 67, 625-633. [CrossRef] [PubMed]

115. Clarke, S.F.; Murphy, E.F.; O’Sullivan, O.; Lucey, A.J.; Humphreys, M.; Hogan, A.; Hayes, P.; O’Reilly, M.; Jeffery, I.B.; WoodMartin, R.; et al. Exercise and associated dietary extremes impact on gut microbial diversity. Gut 2014, 63, 1913-1920. [CrossRef]

116. Mailing, L.J.; Allen, J.M.; Buford, T.W.; Fields, C.J.; Woods, J.A. Exercise and the Gut Microbiome: A Review of the Evidence, Potential Mechanisms, and Implications for Human Health. Exerc. Sport Sci. Rev. 2019, 47, 75-85. [CrossRef]

117. Ali, A.M.; Kunugi, H. Apitherapy for Parkinson's disease: A focus on the effects of propolis and royal jelly. Oxid. Med. Cell. Longev. 2020, 2020, 1727142. [CrossRef]

118. Yazar, T.; Yazar, H.O.; Zayimoglu, E.; Cankaya, S. Incidence of sarcopenia and dynapenia according to stage in patients with idiopathic Parkinson's disease. Neurol. Sci. Off. J. Ital. Neurol. Soc. Ital. Soc. Clin. Neurophysiol. 2018, 39, 1415-1421. [CrossRef]

119. Peball, M.; Mahlknecht, P.; Werkmann, M.; Marini, K.; Murr, F.; Herzmann, H.; Stockner, H.; de Marzi, R.; Heim, B.; Djamshidian, A.; et al. Prevalence and Associated Factors of Sarcopenia and Frailty in Parkinson's Disease: A Cross-Sectional Study. Gerontology 2018, 65, 216-228. [CrossRef]

120. Rempe, R.G.; Hartz, A.M.S.; Bauer, B. Matrix metalloproteinases in the brain and blood-brain barrier: Versatile breakers and makers. J. Cereb. Blood Flow Metab. 2016, 36, 1481-1507. [CrossRef]

121. Inoue, Y.; Hara, H.; Mitsugi, Y.; Yamaguchi, E.; Kamiya, T.; Itoh, A.; Adachi, T. 4-Hydroperoxy-2-decenoic acid ethyl ester protects against 6-hydroxydopamine-induced cell death via activation of Nrf2-ARE and eIF2 $\alpha$-ATF4 pathways. Neurochem. Int. 2018, 112, 288-296. [CrossRef]

122. Xiao, Y.; Zhang, J.; Shu, X.; Bai, L.; Xu, W.; Wang, A.; Chen, A.; Tu, W.Y.; Wang, J.; Zhang, K.; et al. Loss of mitochondrial protein CHCHD10 in skeletal muscle causes neuromuscular junction impairment. Hum. Mol. Genet. 2019, 29, 1784-1796. [CrossRef]

123. Romero-Suarez, S.; Shen, J.; Brotto, L.; Hall, T.; Mo, C.; Valdivia, H.H.; Andresen, J.; Wacker, M.; Nosek, T.M.; Qu, C.K.; et al. Muscle-specific inositide phosphatase (MIP/MTMR14) is reduced with age and its loss accelerates skeletal muscle aging process by altering calcium homeostasis. Aging 2010, 2, 504-513. [CrossRef]

124. Pchitskaya, E.; Popugaeva, E.; Bezprozvanny, I. Calcium signaling and molecular mechanisms underlying neurodegenerative diseases. Cell Calcium 2018, 70, 87-94. [CrossRef]

125. Kunugi, H.; Ali, A.M. Royal Jelly and Its Components Promote Healthy Aging and Longevity: From Animal Models to Humans. Int. J. Mol. Sci. 2019, 20, 4662. [CrossRef] [PubMed]

126. Pronsato, L.; Milanesi, L.; Vasconsuelo, A. Testosterone induces up-regulation of mitochondrial gene expression in murine C2C12 skeletal muscle cells accompanied by an increase of nuclear respiratory factor-1 and its downstream effectors. Mol. Cell. Endocrinol. 2020, 500, 110631. [CrossRef]

127. Church, D.D.; Pasiakos, S.M.; Wolfe, R.R.; Ferrando, A.A. Acute testosterone administration does not affect muscle anabolism. Nutr. Metab. 2019, 16, 56. [CrossRef]

128. Landi, F.; Camprubi-Robles, M.; Bear, D.E.; Cederholm, T.; Malafarina, V.; Welch, A.A.; Cruz-Jentoft, A.J. Muscle loss: The new malnutrition challenge in clinical practice. Clin. Nutr. 2019, 38, 2113-2120. [CrossRef] [PubMed]

129. Walrand, S.; Gryson, C.; Salles, J.; Giraudet, C.; Migne, C.; Bonhomme, C.; Le Ruyet, P.; Boirie, Y. Fast-digestive protein supplement for ten days overcomes muscle anabolic resistance in healthy elderly men. Clin. Nutr. 2016, 35, 660-668. [CrossRef]

130. Boirie, Y.; Guillet, C. Fast digestive proteins and sarcopenia of aging. Curr. Opin. Clin. Nutr. Metab. Care 2018, $21,37-41$. [CrossRef] [PubMed]

131. Tsintzas, K.; Jones, R.; Pabla, P.; Mallinson, J.; Barrett, D.A.; Kim, D.H.; Cooper, S.; Davies, A.; Taylor, T.; Chee, C.; et al. Effect of acute and short-term dietary fat ingestion on postprandial skeletal muscle protein synthesis rates in middle-aged, overweight, and obese men. Am. J. Physiol. Endocrinol. Metab. 2020, 318, E417-E429. [CrossRef] [PubMed]

132. Landi, F.; Calvani, R.; Tosato, M.; Martone, A.M.; Ortolani, E.; Savera, G.; D’Angelo, E.; Sisto, A.; Marzetti, E. Protein Intake and Muscle Health in Old Age: From Biological Plausibility to Clinical Evidence. Nutrients 2016, 8, 295. [CrossRef] 
133. Salles, J.; Cardinault, N.; Patrac, V.; Berry, A.; Giraudet, C.; Collin, M.L.; Chanet, A.; Tagliaferri, C.; Denis, P.; Pouyet, C.; et al. Bee pollen improves muscle protein and energy metabolism in malnourished old rats through interfering with the Mtor signaling pathway and mitochondrial activity. Nutrients 2014, 6, 5500. [CrossRef]

134. Belančić, A. Gut microbiome dysbiosis and endotoxemia-Additional pathophysiological explanation for increased COVID-19 severity in obesity. Obes. Med. 2020, 20, 100302. [CrossRef] [PubMed]

135. Remelli, F.; Vitali, A.; Zurlo, A.; Volpato, S. Vitamin D Deficiency and Sarcopenia in Older Persons. Nutrients 2019, $11,2861$. [CrossRef]

136. Inostroza Flores, G.; Francino Barrera, G.; Jiménez Torres, S. How does vitamin D influence body composition, sarcopenia and lifespan in older persons? A retrospective study of nine years. Nutr. Hosp. 2019, 36, 1067-1073. [CrossRef] [PubMed]

137. Mathieu, S.V.; Fischer, K.; Dawson-Hughes, B.; Freystaetter, G.; Beuschlein, F.; Schietzel, S.; Egli, A.; Bischoff-Ferrari, H.A. Association between 25-Hydroxyvitamin D Status and Components of Body Composition and Glucose Metabolism in Older Men and Women. Nutrients 2018, 10, 1826. [CrossRef]

138. Perna, S.; Alalwan, T.A.; Al-Thawadi, S.; Negro, M.; Parimbelli, M.; Cerullo, G.; Gasparri, C.; Guerriero, F.; Infantino, V.; Diana, M.; et al. Evidence-Based Role of Nutrients and Antioxidants for Chronic Pain Management in Musculoskeletal Frailty and Sarcopenia in Aging. Geriatric 2020, 5, 16. [CrossRef]

139. Ali, A.M.; Kunugi, H.; Abdelmageed, H.A.; Mandour, A.S.; Ahmed, M.E.; Ahmad, S.; Hendawy, A.O. Vitamin K in COVID-19Potential Anti-COVID-19 Effects of Vitamin K Antagonists (VKA) and Fermented Milk Fortified with Bee Honey as a Natural Source of Vitamin K and Probiotics. Fermentation 2021, submitted.

140. Mahajan, A.; Donovan, L.E.; Vallee, R.; Yamamoto, J.M. Evidenced-Based Nutrition for Gestational Diabetes Mellitus. Curr. Diabetes Rep. 2019, 19, 94. [CrossRef]

141. Konishi, K.; Wada, K.; Yamakawa, M.; Goto, Y.; Mizuta, F.; Koda, S.; Uji, T.; Tsuji, M.; Nagata, C. Dietary Soy Intake Is Inversely Associated with Risk of Type 2 Diabetes in Japanese Women but Not in Men. J. Nutr. 2019, 149, 1208-1214. [CrossRef]

142. Konya, J.; Sathyapalan, T.; Kilpatrick, E.S.; Atkin, S.L. The Effects of Soy Protein and Cocoa With or Without Isoflavones on Glycemic Control in Type 2 Diabetes. A Double-Blind, Randomized, Placebo-Controlled Study. Front. Endocrinol. 2019, 10, 296. [CrossRef] [PubMed]

143. Smith, R.E. The Effects of Dietary Supplements That Overactivate the Nrf2/ARE System. Curr. Med. Chem. 2019, 27, 2077-2094. [CrossRef] [PubMed]

144. El Hajj, C.; Fares, S.; Chardigny, J.M.; Boirie, Y.; Walrand, S. Vitamin D supplementation and muscle strength in pre-sarcopenic elderly Lebanese people: A randomized controlled trial. Arch. Osteoporos. 2018, 14, 4. [CrossRef] [PubMed]

145. Thomas, D.T.; Schnell, D.M.; Redzic, M.; Zhao, M.; Abraha, H.; Jones, D.; Brim, H.; Yu, G. Local In Vivo Measures of Muscle Lipid and Oxygen Consumption Change in Response to Combined Vitamin D Repletion and Aerobic Training in Older Adults. Nutrients 2019, 11, 930. [CrossRef] [PubMed]

146. Bode, L.E.; McClester Brown, M.; Hawes, E.M. Vitamin D Supplementation for Extraskeletal Indications in Older Persons. J. Am. Med. Dir. Assoc. 2020, 21, 164-171. [CrossRef]

147. Chiche, A.; Le Roux, I.; von Joest, M.; Sakai, H.; Aguin, S.B.; Cazin, C.; Salam, R.; Fiette, L.; Alegria, O.; Flamant, P.; et al. Injury-Induced Senescence Enables In Vivo Reprogramming in Skeletal Muscle. Cell Stem Cell 2017, 20, 407-414. [CrossRef]

148. Hernandez-Hernandez, J.M.; Garcia-Gonzalez, E.G.; Brun, C.E.; Rudnicki, M.A. The myogenic regulatory factors, determinants of muscle development, cell identity and regeneration. Semin. Cell Dev. Biol. 2017, 72, 10-18. [CrossRef]

149. Zammit, P.S. Function of the myogenic regulatory factors Myf5, MyoD, Myogenin and MRF4 in skeletal muscle, satellite cells and regenerative myogenesis. Semin. Cell Dev. Biol. 2017, 72, 19-32. [CrossRef] [PubMed]

150. Meng, G.; Wang, H.; Pei, Y.; Li, Y.; Wu, H.; Song, Y.; Guo, Q.; Guo, H.; Fukushima, S.; Tatefuji, T.; et al. Effects of protease-treated royal jelly on muscle strength in elderly nursing home residents: A randomized, double-blind, placebo-controlled, dose-response study. Sci. Rep. 2017, 7, 11416. [CrossRef]

151. Madaro, L.; Torcinaro, A.; De Bardi, M.; Contino, F.F.; Pelizzola, M.; Diaferia, G.R.; Imeneo, G.; Bouche, M.; Puri, P.L.; De Santa, F. Macrophages fine tune satellite cell fate in dystrophic skeletal muscle of mdx mice. PLoS Genet. 2019, 15, e1008408. [CrossRef] [PubMed]

152. Zhao, Y.; Jaber, V.; Lukiw, W.J. Secretory Products of the Human GI Tract Microbiome and Their Potential Impact on Alzheimer's Disease (AD): Detection of Lipopolysaccharide (LPS) in AD Hippocampus. Front. Cell. Infect. Microbiol. 2017, 7, 318. [CrossRef] [PubMed]

153. Jeffery, I.B.; Lynch, D.B.; O'Toole, P.W. Composition and temporal stability of the gut microbiota in older persons. ISME J. 2016, 10, 170-182. [CrossRef]

154. Siddharth, J.; Chakrabarti, A.; Pannerec, A.; Karaz, S.; Morin-Rivron, D.; Masoodi, M.; Feige, J.N.; Parkinson, S.J. Aging and sarcopenia associate with specific interactions between gut microbes, serum biomarkers and host physiology in rats. Aging 2017, 9, 1698-1720. [CrossRef]

155. Jang, S.E.; Lim, S.M.; Jeong, J.J.; Jang, H.M.; Lee, H.J.; Han, M.J.; Kim, D.H. Gastrointestinal inflammation by gut microbiota disturbance induces memory impairment in mice. Mucosal Immunol. 2018, 11, 369-379. [CrossRef]

156. Pretorius, L.; Kell, D.B.; Pretorius, E. Iron Dysregulation and Dormant Microbes as Causative Agents for Impaired Blood Rheology and Pathological Clotting in Alzheimer's Type Dementia. Front. Neurosci. 2018, 12, 851. [CrossRef] 
157. Claesson, M.J.; Jeffery, I.B.; Conde, S.; Power, S.E.; O'Connor, E.M.; Cusack, S.; Harris, H.M.; Coakley, M.; Lakshminarayanan, B.; O'Sullivan, O.; et al. Gut microbiota composition correlates with diet and health in the elderly. Nature 2012, 488, 178-184. [CrossRef]

158. Yan, H.; Diao, H.; Xiao, Y.; Li, W.; Yu, B.; He, J.; Yu, J.; Zheng, P.; Mao, X.; Luo, Y.; et al. Gut microbiota can transfer fiber characteristics and lipid metabolic profiles of skeletal muscle from pigs to germ-free mice. Sci. Rep. 2016, 6, 31786. [CrossRef] [PubMed]

159. Ticinesi, A.; Lauretani, F.; Tana, C.; Nouvenne, A.; Ridolo, E.; Meschi, T. Exercise and immune system as modulators of intestinal microbiome: Implications for the gut-muscle axis hypothesis. Exerc. Immunol. Rev. 2019, 25, 84-95. [PubMed]

160. Chen, Y.M.; Wei, L.; Chiu, Y.S.; Hsu, Y.J.; Tsai, T.Y.; Wang, M.F.; Huang, C.C. Lactobacillus plantarum TWK10 Supplementation Improves Exercise Performance and Increases Muscle Mass in Mice. Nutrients 2016, 8, 205. [CrossRef]

161. Bindels, L.B.; Beck, R.; Schakman, O.; Martin, J.C.; De Backer, F.; Sohet, F.M.; Dewulf, E.M.; Pachikian, B.D.; Neyrinck, A.M.; Thissen, J.P.; et al. Restoring specific lactobacilli levels decreases inflammation and muscle atrophy markers in an acute leukemia mouse model. PLoS ONE 2012, 7, e37971. [CrossRef] [PubMed]

162. Hua, X.; Liu, S.; Liao, J.F.; Wen, W.; Long, Z.Q.; Lu, Z.J.; Guo, L.; Lin, H.X. When the Loss Costs Too Much: A Systematic Review and Meta-Analysis of Sarcopenia in Head and Neck Cancer. Front. Oncol. 2019, 9, 1561. [CrossRef]

163. Bruyere, O.; Beaudart, C.; Ethgen, O.; Reginster, J.Y.; Locquet, M. The health economics burden of sarcopenia: A systematic review. Maturitas 2019, 119, 61-69. [CrossRef] [PubMed]

164. Morley, J.E. Treatment of sarcopenia: The road to the future. J. Cachexia Sarcopenia Muscle 2018, 9, 1196-1199. [CrossRef] [PubMed]

165. Rooks, D.; Roubenoff, R. Development of Pharmacotherapies for the Treatment of Sarcopenia. J. Frailty Aging 2019, 8, 120-130. [CrossRef] [PubMed]

166. Ali, A.M.; Hendawy, A.O. Royal Jelly Acid, 10-Hydroxy-Trans-2-Decenoic Acid, for Psychiatric and Neurological Disorders: How helpful could it be?! Edelweiss J. Food Sci. Technol. 2019, 1, 1-4. [CrossRef]

167. Ali, A.M.; Kunugi, H. Bee honey protects astrocytes against oxidative stress: A preliminary in vitro investigation. Neuropsychopharmacol. Rep. 2019, 39, 312-314. [CrossRef]

168. Mossalayi, M.D.; Rambert, J.; Renouf, E.; Micouleau, M.; Mérillon, J.M. Grape polyphenols and propolis mixture inhibits inflammatory mediator release from human leukocytes and reduces clinical scores in experimental arthritis. Phytomedicine 2014, 21, 290-297. [CrossRef]

169. Tomasin, R.; de Andrade, R.S.; Gomes-Marcondes, M.C. Oral Administration of Aloe vera (L.) Burm. f. (Xanthorrhoeaceae) and Honey Improves the Host Body Composition and Modulates Proteolysis Through Reduction of Tumor Progression and Oxidative Stress in Rats. J. Med. Food 2015, 18, 1128-1135. [CrossRef]

170. Santos, N.W.; Yoshimura, E.H.; Mareze-Costa, C.E.; Machado, E.; Agustinho, B.C.; Pereira, L.M.; Brito, M.N.; Brito, N.A.; Zeoula, L.M. Supplementation of cow milk naturally enriched in polyunsaturated fatty acids and polyphenols to growing rats. PLoS ONE 2017, 12, e0172909. [CrossRef]

171. Maaroufi, H. The Spike Protein S1 Subunit of SARS-CoV-2 Contains an LxxIxE-like Motif that is Known to Recruit the Host PP2A-B56 Phosphatase. bioRxiv 2020. [CrossRef]

172. Jahrami, H.A.; Alsibai, J.; Clark, C.C.T.; Faris, M.e.A.-I.E. A systematic review, meta-analysis, and meta-regression of the impact of diurnal intermittent fasting during Ramadan on body weight in healthy subjects aged 16 years and above. Eur. J. Nutr. 2020, 59, 2291-2316. [CrossRef] [PubMed]

173. Domaszewski, P.; Konieczny, M.; Pakosz, P.; Baczkowicz, D.; Sadowska-Krępa, E. Effect of a Six-Week Intermittent Fasting Intervention Program on the Composition of the Human Body in Women over 60 Years of Age. Int. J. Environ. Res. Public Health 2020, 17, 4138. [CrossRef] [PubMed]

174. Bradshaw, P.C.; Seeds, W.A.; Miller, A.C.; Mahajan, V.R.; Curtis, W.M. COVID-19: Proposing a Ketone-Based Metabolic Therapy as a Treatment to Blunt the Cytokine Storm. Oxid. Med. Cell. Longev. 2020, 2020, 6401341. [CrossRef] [PubMed] 